\title{
Effect of Aging on the Microstructure and Optical Properties of Translucent $\mathrm{ZrO}_{2}$ Ceramics
}

\section{Utjecaj starenja na mikrostrukturu i optička svojstva translucentne $\mathrm{ZrO}_{2}$ keramike}

\author{
${ }^{1}$ Dental Office, 10000 Zagreb, Croatia \\ Stomatološka ordinacija, 10000 Zagreb, Hrvatska \\ 2 Faculty of Graphic Arts, 10000 Zagreb, Croatia \\ Grafički fakultet Sveučilišta u Zagrebu, 10000 Zagreb, Hrvatska \\ ${ }^{3}$ Dental Clinic, University Hospital Centre Zagreb, 10000 Zagreb, Croatia; School of Dental Medicine University of Zagreb \\ Klinika za stomatologiju Kliničkoga bolničkoga centra Zagreb, 10000 Zagreb; Stomatološki fakultet Sveučilišta u Zagrebu
}

\section{Abstract}

Objectives: The development and placement of translucent zirconia ceramics on the dental materials market is in full swing. This research aimed to investigate how aging protocols affect the microstructure, color parameters and translucency of a new-generation monolithic zirconia ceramic. Material and methods: Translucent zirconia ceramics KATANA-Zirconia STML with different surface treatments (as sintered - control, glazed, polished) was tested using two aging protocols (hydrothermal degradation in autoclave at $134^{\circ} \mathrm{C}$ and 2 bars for three hours, chemical degradation in four-percent acetic acid at $80^{\circ} \mathrm{C}$ for 16 hours) in order to examine phase composition using X-ray diffraction analysis and $\Delta \mathrm{E}, \Delta \mathrm{L}$ and $\Delta \mathrm{C}$ color parameters through spectrophotometry. The translucency parameter (TP) was calculated using parameters $L^{*}, a^{*}$ and $b^{*}$ on a black and white surface. Results: Regardless of the surface treatment, aging protocols did not cause a tetragonal-to-monoclinic phase transformation, although hydrothermal degradation in the autoclave transformed the hybrid tetragonal-cubic structure of all specimens to a tetragonal one. All polished and glazed specimens during chemical degradation demonstrated a significant color change $\Delta \mathrm{E}$. Lightness $\Delta \mathrm{L}$ significantly changed in polished specimens aged in the autoclave. In all specimens, $\Delta C$ underwent a change manifested through statistically insignificant yellowing. None of the aging protocols altered the translucency of specimens. Conclusions: Aging, regardless of the final surface treatment, did not manifest a monoclinic phase in the specimens. A tetragonal-cubic microstructure dominates. Unlike polishing, glazing the surface of translucent zirconia ceramics contributed to minor changes in color, lightness and chromaticity. The translucency of translucent zirconia ceramics remains stable regardless of aging and surface treatment.
Received: March 30, 2021

Accepted: May 31, 2021

Address for correspondence Professor Ketij Mehulić, PhD, University of Zagreb School of Dental Medicine Department of Fixed Prosthodontics 10000 Zagreb, Croatia Phone: +38514802111 mehulic@sfzg.hr

MeSH terms: Dental Materials; Zirconium

Author keywords: Translucent zirconia; Monolithic zirconia; Cubic zirconia

\section{Introduction}

Owing to its excellent mechanical properties, zirconia ceramics (partially stabilized zirconia) is widely employed in dental medicine (1). Due to its highly opaque character, it has been used as core material in bilayer systems, meaning that the final shape and appearance of a restoration have been attained by veneering a ceramic with better optical properties $(2,3)$. Two main problems arise in the clinical application of these materials. The first problem is the chipping of veneering porcelains. The cohesive fracture is caused by a strain exerted on the more fragile material due to a discord in the coefficient of thermal expansion between the two materials (core and veneering) (3). Another problem is the "aging" phenomenon, i.e. low temperature degradation (LTD) (4-10). Aging is described as a spontaneous transformation of a tetragonal crystal structure into a monoclinic one in a moist

\section{Uvod}

Zahvaljujući izvrsnim mehaničkim svojstvima, cirkonijoksidna keramika (parcijalno stabilizirani cirkonijev oksid) široko se primjenjuje u dentalnoj medicini (1). Zbog iznimne opaknosti primjenjivala se kao jezgreni materijal u dvoslojnim sustavima, što znači da se konačni oblik i izgled nadomjestka dobivao slojevanjem keramikom boljih optičkih svojstava $(2,3)$. U kliničkoj primjeni tih materijala dva su glavna problema. Prvi je odlamanje obložne keramike - chipping. Uzrok je naprezanje koje nastaje u slabijem materijalu zbog neusklađenosti koeficijenata termičkog istezanja između dvaju materijala (jezgrenoga i obložnoga) (3). Drugi problem je fenomen starenja, odnosno degradacije pri niskim temperaturama (low temperature degradation - LTD) $(4-10)$. Starenje se opisuje kao spontana transformacija tetragonske kristalne strukture u monoklinsku u vlažnom mediju pri niskim 
medium at a room temperature (4-10). LTD causes the expansion of grains' volume (4-5\%), and consequently strains grain boundaries, which results in an emergence of microcracks in the material (4-10). On the other hand, the expansion of the volume of grains can reduce crack propagation in the bulk of the material by reducing or closing the crack; this phenomenon is called transformation toughening (4-11) and it is the cause for high values of the strength of the material and toughness $(8,12,13)$. Spontaneous phase transformation of zirconia ceramics is prevented by adding different percentages of stabilizers, such as yttrium, calcium, magnesium or cerium oxide $(3,6-8)$. Zirconia ceramics of the first (core in bilayer systems) $(1,3,6)$ and second generation (older monolithic ceramics) $(3-5,9,10)$ contain approximately $2-3 \mathrm{~mol} \%$ of yttrium oxide $\left(\mathrm{Y}_{2} \mathrm{O}_{3}\right)$ as the structure stabilizer. In spite of the addition of a stabilizer, exposing first-generation and second-generation zirconia ceramics to hydrothermal degradation in an autoclave always results in tetragonal-to-monoclinic transformation on the surface, which is exposed to moist environment and temperature shifts, in a similar way as the exposed side of a restoration in the oral cavity (3-10). The loading of the material during chewing causes the emergence of new and expansion of existing micro-cracks, thus triggering the advancement of tetragonal-to-monoclinic transformation from the surface into the depth, which may eventually result in restoration fracture (3-10). The expansion of volume causes monoclinic grains to rise above the surface of the materials, thereby increasing the roughness of the materials and the consequential wear of antagonists in the chewing process (14).

Translucency is the main esthetic reason in choosing materials for fixed prosthetic restorations (15). Insufficient translucency of first-generation and second-generation zirconia ceramics has limited their application in the esthetically more demanding anterior part of dental arch. Zhang et al. reported an increased manifestation $(50 \%)$ of a cubic crystal structure in translucent zirconia ceramics with $5 \mathrm{~mol} \%$ of yttrium oxide (fully stabilized zirconia) (16). A cubic crystal lattice is resistant to transformation, which should eliminate the problem of aging. Dispersion on the grains of a cubic crystal lattice is abated, while transmission through material is amplified, which fosters translucency and the possibility of imitating dental hard tissues (17). According to Kolakarnprasert et al., grain size differs in different translucent materials (17). They reported that KATANA-Zirconia UTML had the largest grain size $(4.05 \pm 0.85 \mu \mathrm{m})$ and the highest cubic phase percentage, followed by Katana STML $(2.81 \pm 0.17$ $\mu \mathrm{m})$ and finally Katana ML $(0.63 \pm 0.3 \mu \mathrm{m})$, which also displayed the lowest share of cubic phase in its structure (17). Due to the aforementioned problems with first-generation and second-generation zirconia ceramics, a need arose for a new, third-generation zirconia ceramic which would eliminate those problems. By exposing materials to aging protocols, one may predict their performance in the oral cavity over a longer period $(4-10,16,17)$.

The aim of this research was to evaluate the effect of hydrothermal and chemical aging protocols on microstructure, color parameters, i.e. color stability and translucency temperaturama (4 - 10). Zbog LTD-a nastaje volumna ekspanzija zrna $(4-5 \%)$ te se stvara naprezanje na granicama zrna koje rezultira nastankom mikropukotina u materijalu (4 - 10). S druge strane, volumna ekspanzija zrna može spriječiti širenje postojeće mikropukotine njezinim smanjenjem ili zatvaranjem, što se naziva transformacijsko očvršćenje (4 - 11), a to je i razlog za visoke vrijednosti čvrstoće i tvrdoće tih materijala $(8,12,13)$. Spontana fazna transformacija cirkonij-oksidne keramike sprječava se dodavanjem stabilizatora u različitom postotku, kao što su itrijev, kalcijev, magnezijev ili cerijev oksid $(3,6-8)$. Cirkonij-oksidne keramike prve generacije (za jezgru kod dvoslojnih sustava) $(1,3,6)$ i druge generacije (starije monolitne) $(3-5,9,10)$ sadržavaju 2 do $3 \%$ molekularnog udjela itrijeva oksida $\left(\mathrm{Y}_{2} \mathrm{O}_{3}\right)$ kao stabilizatora strukture. Unatoč dodatku stabilizatora, izlaganje cirkonij-oksidne keramike prve i druge generacije hidrotermalnoj degradaciji u autoklavu uvijek završava tetragonskomonoklinskom transformacijom i to na površini koja je izložena vlazi i promjeni temperature, što odgovara eksponiranoj strani nadomjestka u usnoj šupljini $(3-10)$. Opterećenje primijenjeno na materijal pri žvačnoj funkciji izaziva nastanak novih mikropukotina i širenje postojećih, a one su okidač za napredovanje tetragonsko-monoklinske transformacije s površine u dubinu, što $s$ vremenom može rezultirati lomljenjem nadomjestka (3 - 10). Volumna ekspanzija monoklinskih zrna potiče njihovo izdizanje iznad površine materijala, čime se povećava hrapavost materijala i posljedično trošenje antagonista u funkciji (14).

Translucencija se navodi kao glavno estetsko obilježje u izboru materijala u fiksnoprotetičkoj terapiji (15). Nedovoljna translucencija cirkonij-oksidnih keramika prve i druge generacije ograničila je njihovu primjenu u estetski zahtjevnijem, prednjem dijelu zubnoga niza. Zhang i suradnici, istražujući translucentnu cirkonij-oksidnu keramiku, navode pojavu kubične kristalne strukture u većem postotku (50 \%) s $5 \%$ molekularnog udjela itrijeva oksida (potpuno stabilizirani cirkonijev oksid) (16). Kubična kristalna rešetka otporna je na transformaciju, čime bi problem starenja trebao biti eliminiran. Na zrnima kubične kristalne rešetke smanjen je rasap svjetlosti, a povećana transmisija kroz materijal, pa se postiže bolja translucencija i veća mogućnost imitiranja tvrdih zubnih tkiva (17). Prema Kolakarnprasertu i suradnicima, ta se veličina zrna razlikuje od materijala do materijala (17). U njihovu istraživanju materijal KATANA-Zirconia UTML ima najveća zrna $(4,05 \pm 0,85 \mu \mathrm{m})$ i najveći postotak kubične faze, slijedi ga KATANA STML $(2,81 \pm 0,17 \mu \mathrm{m})$ i naposljetku KATANA ML $(0,63 \pm 0,3$ $\mu \mathrm{m})$ koji ujedno ima najmanji udio kubične faze u strukturi (17). Zbog opisanih problema prve i druge generacije cirkonij-oksidne keramike pojavila se potreba za novom, trećom generacijom kojom bi se ti problemi otklonili i koja je od pojave na tržištu postala predmetom mnogobrojnih istraživanja. Izlaganjem materijala protokolima starenja može se predvidjeti njegovo ponašanje u usnoj šupljini tijekom duljeg razdoblja $(4-10,16,17)$. Cilj ovog istraživanja bio je ispitati utjecaj protokola starenja na mikrostrukturu, kolorne parametre i translucenciju monolitne translucentne cirkonij-oksidne keramike. 
of monolithic translucent multilayered zirconia ceramic. The following hypotheses have been tested:

1. Hydrothermal degradation in an autoclave and chemical degradation in a corrosive medium do not affect the microstructure of specimens.

2. Hydrothermal degradation in an autoclave and chemical degradation in a corrosive medium bring about color changes expressed by parameters $\mathrm{CIE} \Delta \mathrm{E}, \mathrm{CIE} \Delta \mathrm{L}$ and CIE $\Delta \mathrm{C}$, which are within clinically acceptable values over a longer period of application.

3. Hydrothermal degradation in an autoclave and chemical degradation in a corrosive medium do not affect the translucency of monolithic translucent zirconia ceramic.

The microstructure and translucency of monolithic translucent zirconia ceramic correlate.

\section{Material and methods}

\section{Specimen Preparation}

Monolithic translucent zirconia ceramics KATANA-Zirconia Super Translucent Multi Layered - STML (Kuraray Noritake Dental Inc., Tokyo, Japan), shade A2 (Table 1) was used in the study. Overall, 18 specimens $(11 \mathrm{~mm} \times 11 \mathrm{~mm}$ $\mathrm{x} 1.5 \mathrm{~mm}$ with $\pm 5 \%$ tolerance) were fabricated using the $\mathrm{CAD} / \mathrm{CAM}$ technique in a milling machine (Zenotec Easy Wieland, Pforzheim, Germany) and sintered in a furnace (Wieland, Pforzheim, Germany) according to the manufacturer's instructions $\left(2\right.$ hours at $1550{ }^{\circ} \mathrm{C}$ ). The heating rate of $10^{\circ} \mathrm{C} / \mathrm{min}$ was employed until the sintering temperature was reached. The same dynamics was repeated in cooling protocol after the final sintering. Depending on the surface treatment, the specimens were divided into two groups. Eight specimens were glazed following the manufacturer's instructions (G1G8), while eight other specimens were polished (P1-P8) with diamond rubbers for porcelain (Ceragloss, EDENTA AG, Hauptstrasse 7, Switzerland) and cooled with water. Each group was further divided into two subgroups, according to the aging protocol applied. The remaining two specimens received no surface treatment and acted as control specimens in the research $(\mathrm{C} 1, \mathrm{C} 2)$.

\section{Null Measurements and Analyses}

An X-ray diffraction analysis (Philips PW 1820 diffractometer, Philips Co., Amsterdam, Netherlands) was performed on two polished samples (P1, P5) so as to attain the initial crystal structure, which was assumed to be identical in all specimens. Two ceramic tiles (P1, P5) were subjected to CuK-alpha radiation in the space between $10^{\circ}$ and $70^{\circ}$ of the 2theta angle, with a step size of $0.02^{\circ}$ and step time of 1 s/step.

The initial values of color parameters $\mathrm{L}^{*}, \mathrm{a}^{*}$ and $\mathrm{b}^{*}$ on all specimens, including the control ones, were calculated with an X-rite Exact spectrophotometer (Grand Rapids, Michi-
Testirat će se sljedeće hipoteze:

1. hidrotermalna degradacija u autoklavu i kemijska degradacija u korozivnom mediju neće utjecati na mikrostrukturu uzoraka

2. hidrotermalna degradacija u autoklavu i kemijska degradacija u korozivnom mediju rezultirat će kolornim promjenama izraženima parametrima $\mathrm{CIE} \Delta \mathrm{E}, \mathrm{CIE} \Delta \mathrm{L}$ i CIE $\Delta \mathrm{C}$ koje su unutar klinički prihvatljivih vrijednosti tijekom dulje primjene

3. hidrotermalna degradacija u autoklavu i kemijska degradacija u korozivnom mediju neće utjecati na translucenciju monolitne translucentne cirkonij-oksidne keramike

4. u korelaciji su mikrostruktura i translucencija monolitne translucentne cirkonij-oksidne keramike.

\section{Materijal i postupci}

\section{Priprema uzoraka}

U istraživanju je korištena monolitna translucentna cirkonij-oksidna keramika KATANA-Zirconia Super Translucent Multi Layered - STML (Kuraray Noritake Dental Inc., Tokio, Japan), boje A2 (tablica 1.). Izrađeno je 18 uzora$\mathrm{ka}(11 \mathrm{~mm} \times 11 \mathrm{~mm} \times 1,5 \mathrm{~mm}$ u toleranciji $\pm 5 \%) \mathrm{CAD} /$ CAM tehnikom u glodalici Zenotec Easy Wieland (Wieland, Pforzheim, Njemačka) sinteriranjem u peći Wieland (Wieland, Pforzheim, Njemačka) prema uputi proizvođača $(2 \mathrm{~h}$ na $1550{ }^{\circ} \mathrm{C}$ ). Porast temperature do temperature sinteriranja je $10^{\circ} \mathrm{C} / \mathrm{min}$. Ista je dinamika snižavanja temperature - hlađenja nakon završenog sinteriranja. Ovisno o završnoj obradi površine uzorci su podijeljeni u dvije skupine. Osam uzoraka glazirano je prema uputi proizvođača (G1 - G8), a osam polirano dijamantnim gumicama za keramiku Ceragloss tvrtke EDENTA AG (Hauptstrasse 7, Švicarska) uz vodeno hlađenje (P1 - P8). Skupine su podijeljene u po dvije podskupine, ovisno o vrsti provedenog eksperimentalnog protokola starenja. Preostala dva uzorka nisu površinski obrađivani i bili su kontrolni uzorci u istraživanju $(\mathrm{C} 1, \mathrm{C} 2)$.

\section{Nulta mjerenja i analize}

$\mathrm{Na}$ dvama poliranim uzorcima (P1, P5) učinjena je difrakcijska analiza X-zrakama radi dobivanja početne kristalne strukture, uz pretpostavku da je ona jednaka u svim uzorcima (difraktometar Philips PW 1820, Philips Co., Amsterdam, Nizozemska). Dvije keramičke pločice (P1, P5) mjerene su na CuKalfa zračenju u području 2theta kuta: od $10^{\circ}$ do $70^{\circ}$, u koraku od $0,02^{\circ}$ i vremenom prikupljanja od 1s/step.

$\mathrm{Na}$ svim uzorcima, uključujući i kontrolne, izmjerene su početne vrijednosti kolornih parametara $\mathrm{L}^{*}, \mathrm{a}^{*} \mathrm{i} \mathrm{b}^{*}$ spektrofotometrom X-rite Exact (Grand Rapids, Michigan, SAD). Uređaj je najprije kalibiriran i namještene su sve postavke
Material $\bullet$ Materijal

KATANA-Zirconia STML

\section{Compound share $\bullet$ Udjeli spojeva (\%)}

\begin{tabular}{|c|c|}
\hline $\mathrm{ZrO}_{2}$ & -86 \\
\hline $\mathrm{Y}_{2}$ & $-11.5-12$ \\
\hline $\mathrm{HfO}_{2}$ & $-2-2.5$ \\
\hline
\end{tabular}


gan, USA). The instrument was calibrated and all the settings were adjusted before measuring (measurement mode 0 , light source D50, standard observer $2^{\circ}$ ). The aperture size was 2 $\mathrm{mm}$. Five measurements were conducted for each specimen on a black surface and a white surface. Changes in color and lightness as well as the chromaticity of specimens were expressed through CIE $\Delta \mathrm{E}, \mathrm{CIE} \Delta \mathrm{L}$ and $\mathrm{CIE} \Delta \mathrm{C}$ values, which were calculated using the $\mathrm{CIE} \Delta \mathrm{E}_{2000}$ formula. Lower $\Delta \mathrm{E}$ values denote a minor colorimetric difference between two points representing colors in the color coordinate system. $\Delta \mathrm{E}$ values under 3.5 are considered to be clinically acceptable in the conditions of the oral cavity (15). The translucency parameter (TP) was extracted from $L^{*}, a^{*}$ and $b^{*}$ parameters on black and white surfaces using the following formula:

$$
\mathrm{TP}=\left[\left(\mathrm{L}^{*} \mathrm{w}-\mathrm{L}^{*} \mathrm{~b}\right)^{2}+\left(\mathrm{a}^{*} \mathrm{w}-\mathrm{a}^{*} \mathrm{~b}\right)^{2}+\left(\mathrm{b}^{*} \mathrm{w}-\mathrm{b}^{*} \mathrm{~b}\right)^{2}\right]^{1 / 2},
$$

where $w$ and $b$ denote $L^{*}$, $a^{*}$ and $b^{*}$ values measured on both a white surface and a black surface.

\section{Experimental Protocols}

All glazed and polished specimens were divided into four subgroups (G1-G4, G5-G8, P1-P4, P5-P8) according to the type of experimental protocol they were subjected to (Figure 1). Four glazed specimens (G1-G4) and four polished specimens (P1-P4) were sterilized in an autoclave (SKO7, Faro, Italy) for a period of three hours, at a temperature of $134^{\circ} \mathrm{C}$ and under 313-318 kPa of pressure (six 30-minute cycles). Distilled water was used for sterilization. Four glazed (G5G8) and four polished specimens (P5-P8) were placed in a 1000 -mL glass measuring flask. A 2.49-pH corrosive medium (four-percent acetic acid $\left(\mathrm{CH}_{3} \mathrm{COOH}\right)$ ) was added and the specimens were submerged in the medium for 16 hours at a temperature of $80^{\circ} \mathrm{C}$ (ISO 6872).

Control specimens $(\mathrm{C} 1, \mathrm{C} 2)$ were not subjected to experimental protocols, but were kept at a room temperature of 20 ${ }^{\circ} \mathrm{C}$ and under a standard pressure of $1 \mathrm{~atm}$ throughout the duration of the research. uređaja prije mjerenja (mjerni mod 0, izvor svjetlosti D50, standardni promatrač $2^{\circ}$ ). Mjerni otvor iznosio je $2 \mathrm{~mm}$. Provedeno je po pet mjerenja na svakom uzorku, na crnoj i bijeloj podlozi. Kolorne razlike, promjene svjetline i kromatičnosti uzoraka izražene su parametrima CIE $\Delta \mathrm{E}, \mathrm{CIE} \Delta \mathrm{L}$ i CIE $\Delta \mathrm{C}$ izračunatima s pomoću formule $\mathrm{CIE} \Delta \mathrm{E}_{2000}$. Niže vrijednosti $\Delta \mathrm{E}$ znače manju kolorimetrijsku razliku između dviju točaka koje opisuju boje u koordinatnom sustavu boja. Vrijednosti $\Delta \mathrm{E}$ do 3,5 u uvjetima usne šupljine smatraju se klinički prihvatljivima (15). Iz parametara $L^{*}, a^{*} \mathrm{i} b^{*}$ na crnoj i bijeloj podlozi, izračunat je parametar translucencije (TP) prema formuli:

$$
\mathrm{TP}=\left[\left(\mathrm{L}^{*} \mathrm{w}-\mathrm{L}^{*} \mathrm{~b}\right)^{2}+\left(\mathrm{a}^{*} \mathrm{w}-\mathrm{a}^{*} \mathrm{~b}\right)^{2}+\left(\mathrm{b}^{*} \mathrm{w}-\mathrm{b}^{*} \mathrm{~b}\right)^{2}\right]^{1 / 2},
$$

gdje su w i b oznake za vrijednosti $L^{*}, a^{*}$ i b* izmjerene na bijeloj i crnoj podlozi.

\section{Eksperimentalni protokoli}

Svi glazirani i svi polirani uzorci su, ovisno o vrsti provedenog eksperimentalnog protokola, podijeljeni u četiri podskupine (G1 - G4, G5 - G8, P1 - P4, P5 - P8) (slika 1.). Četiri glazirana uzorka $(\mathrm{G} 1-\mathrm{G} 4)$ i četiri polirana uzorka (P1 - P4) sterilizirana su tri sata u autoklavu (SKO7, Faro, Italija) na temperaturi od $134^{\circ} \mathrm{C}$ pod tlakom od 313 do $318 \mathrm{kPa}$ (6 ciklusa po 30 minuta). Za sterilizaciju je korištena destilirana voda. Četiri glazirana (G5 - G8) i četiri polirana uzorka (P5 - P8) postavljena su u staklenu mjernu tikvicu volumena $1000 \mathrm{~mL}$ te im je dodan korozivni medij [4-postotna otopina octene kiseline $\left.\left(\mathrm{CH}_{3} \mathrm{COOH}\right)\right] \mathrm{pH}$ vrijednosti 2,49 tako da su potpuno bili uronjeni u njega 16 sati na temperaturi od $80{ }^{\circ} \mathrm{C}$ (ISO 6872).

Kontrolni uzorci (C1, C2) nisu izlagani eksperimentalnim protokolima, nego su tijekom istraživanja čuvani na standardnoj temperaturi od $20^{\circ} \mathrm{C}$ pri standardnom tlaku od $1 \mathrm{~atm}(101325 \mathrm{~Pa})$.

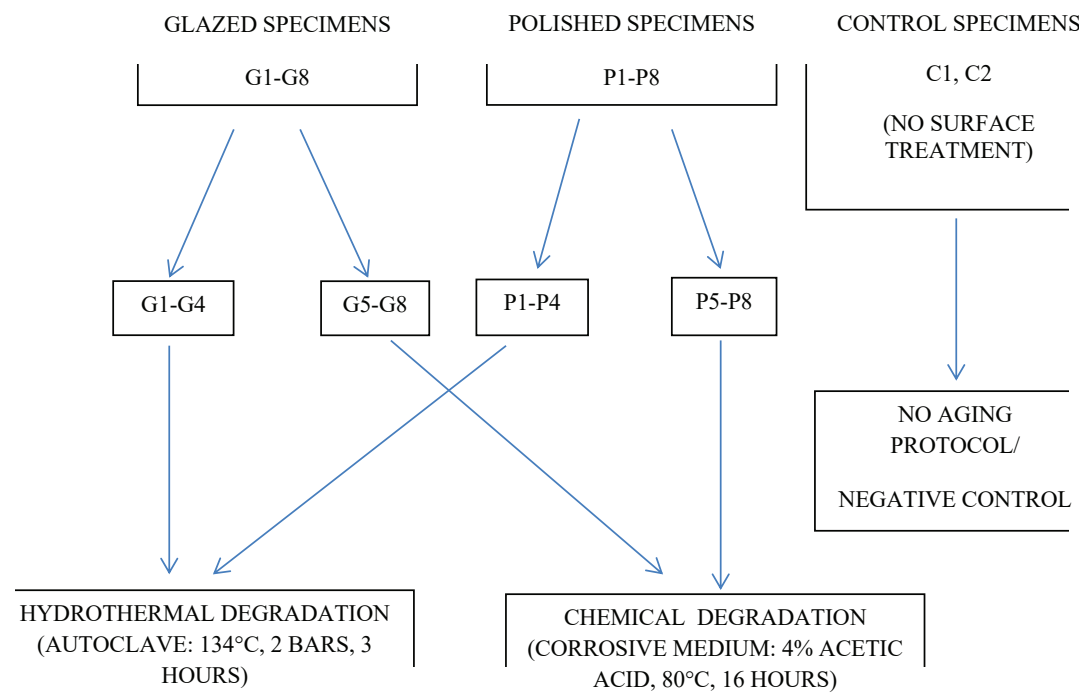

Figure 1 Graphic division of groups of specimens.

Slika 1. Shematski prikaz podjele uzoraka 
After the aging protocols, the same measurements and analyses from the beginning of the research were repeated on all specimens and one specimen from each subgroup (G1, G5, P1 and P5) was subjected to an X-ray diffraction analysis.

\section{Statistical Analysis}

The obtained results are displayed in figures and tables. In order to analyze the statistical significance of CIE $\Delta \mathrm{E}$, CIE $\Delta \mathrm{L}$ and CIE $\Delta \mathrm{C}$ values as well as the significance of the difference in TP values before and after experimental protocols, the Tukey test, with a $95 \%$ confidence interval, was employed along with the One-way ANOVA comparison procedure for detecting differences between groups with regard to the examined parameters. All P values below 0.05 were deemed to be statistically significant. The XLSTAT software was used in the analysis.

\section{Results}

The results of a XRD analysis conducted on polished specimens from both subgroups (P1, P5) before aging protocols (Figure 2) have revealed the diffraction maximum of tetragonal zirconia (position at about $30^{\circ} 2 \mathrm{Theta}$ ) and cubic phase peaks. Phase shares are expressed as percentages. The share of the tetragonal phase was $62.7 \%$, while the share of the cubic phase was $37.3 \%$. Phase composition analyses of glazed (G1) and polished (P1) specimens exposed to hydrothermal degradation in an autoclave revealed that the cubic phase fully transitioned into the tetragonal one (Figure 3). The phase composition of both specimens exposed to chemi-
Nakon protokola starenja na svim uzorcima provedena su ista mjerenja i analize kao i na početku istraživanja. Difrakcijska analiza X-zrakama nakon protokola obavljena je na jednom uzorku iz svake podskupine (G1, G5, P1 i P5).

\section{Statistička analiza}

Rezultati su prikazani grafički i tablično. Za analizu statističke značajnosti vrijednosti CIE $\Delta \mathrm{E}$, CIE $\Delta \mathrm{L}$ i CIE $\Delta \mathrm{C}$, te značajnosti razlika u vrijednostima TP-a prije i poslije eksperimentalnih protokola korišsten je Tukeyjev test s 95 -postotnom značajnosti te ANOVA multiple comparison za detekciju razlika između skupina za ispitivane parametre. Sve P vrijednosti manje od 0,05 smatrale su se statistički značajnima. Za analizu je korišsten programski paket XLSTAT.

\section{Rezultati}

Rezultati difrakcijske analize poliranih uzoraka iz obiju podskupina (P1, P5) prije protokola starenja (slika 2.) pokazuju difrakcijski maksimum tetragonskog cirkonijeva oksida (pozicija oko $30^{\circ} 2 \mathrm{Theta}$ ) te pikove kubične faze. Udjeli faza prikazani su u postotcima. Udio tetragonske faze iznosio je $62,7 \%$, a udio kubične faze $37,3 \%$. Analize faznih sastava glaziranog (G1) i poliranog (P1) uzorka koji su bili izloženi hidrotermalnoj degradaciji u autoklavu pokazuju da je kubična faza posve prešla u tetragonsku (slika 3.). Na oba uzorka izložena kemijskoj degradaciji (G5, P5) u korozivnom mediju fazni sastav ostao je gotovo nepromijenjen (slika 4.).

\begin{tabular}{|c|c|c|c|c|c|c|}
\hline $\begin{array}{ll}\text { Table } 2 & \text { Dis } \\
& \text { and } \\
\text { Tablica 2. } & \text { Prik } \\
& \text { poli }\end{array}$ & $\begin{array}{l}\text { y of value interv } \\
\text { ntrol }(C 1, C 2) \mathrm{sp} \\
\text { intervala vrijedr } \\
\text { ih }(P 1-P 8) \text { i kc }\end{array}$ & $\begin{array}{l}\text { s for } \Delta \mathrm{E}, \Delta \mathrm{L} \text { and } \Delta \mathrm{C} \text { wit } \\
\text { cimens (Tukey test with } \\
\text { sti } \Delta \mathrm{E}, \Delta \mathrm{L} \mathrm{i} \Delta \mathrm{C} \text { sa sredr } \\
\text { trolnih }(\mathrm{C} 1, \mathrm{C} 2) \text { uzorak }\end{array}$ & $\begin{array}{l}\text { their average va } \\
\text { 95\% confidenc } \\
\text { m vrijednostima } \\
\text { Tukeyjev test s }\end{array}$ & $\begin{array}{l}\text { es of } \mathrm{AMs} \text { ( } \Delta \mathrm{E}_{\text {avg }}, \Delta \mathrm{L}_{\text {avg }} \text {, } \\
\text { interval). } \\
\text { ritmetičkih sredina }(\Delta \mathrm{E} \\
\text { 5-postotnim intervalom }\end{array}$ & $\begin{array}{l}\mathrm{C}_{\text {avg }} \text { of glazed (G } \\
\left.\text { d, } \Delta \mathrm{L}_{\text {sred }}, \Delta \mathrm{C}_{\text {sred }}\right) \mathrm{g} \\
\text { ouzdanosti) }\end{array}$ & $\begin{array}{l}\text {-G8), polished (P1-P8) } \\
\text { ziranih (G1 - G8), }\end{array}$ \\
\hline $\begin{array}{c}\text { Specimen } \\
\text { Uzorak }\end{array}$ & $\begin{array}{c}\Delta \mathrm{E} \\
\mathrm{AM} \pm \mathrm{SD} \bullet \\
\mathrm{AS} \pm \mathrm{SD}\end{array}$ & $\begin{array}{c}\Delta \mathrm{E}_{\text {avg }} \\
\text { (average value of } \\
\text { arithmetical means) } \\
\Delta \mathrm{E}_{\text {sred }} \\
\text { (srednja vrijednost } \\
\text { aritmetičkih sredina) }\end{array}$ & $\begin{array}{c}\Delta \mathrm{L} \\
\mathrm{AM} \pm \mathrm{SD} \\
\mathrm{AS} \pm \mathrm{SD}\end{array}$ & $\begin{array}{c}\Delta \mathrm{L}_{\text {avg }} \\
\text { (average value of } \\
\text { arithmetical means) } \\
\Delta \mathrm{L}_{\text {sred }} \\
\text { (srednja vrijednost } \\
\text { aritmetičkih sredina) }\end{array}$ & $\begin{array}{c}\Delta \mathrm{C} \\
\mathrm{AM} \pm \mathrm{SD} \\
\mathrm{AS} \pm \mathrm{SD}\end{array}$ & $\begin{array}{c}\Delta \mathrm{C}_{\text {avg }} \\
\text { (average value of } \\
\text { arithmetical means) } \\
\Delta \mathrm{C}_{\text {sred }} \\
\text { (srednja vrijednost } \\
\text { aritmetičkih sredina) }\end{array}$ \\
\hline G1 & $2.057 \pm 0.791$ & \multirow{4}{*}{ G1-G4: $\mathbf{1 . 6 4}$} & $0.556 \pm 1.043$ & \multirow{4}{*}{ G1-G4: $\mathbf{0 . 4 7}$} & $0.891 \pm 1.368$ & \multirow{4}{*}{ G1-G4: $\mathbf{0 . 2 8}$} \\
\hline G2 & $1.526 \pm 0.876$ & & $-0.088 \pm 1.156$ & & $-0.025 \pm 1.516$ & \\
\hline G3 & $2.057 \pm 0.826$ & & $1.236 \pm 1.090$ & & $-0.597 \pm 1.429$ & \\
\hline G4 & $0.799 \pm 0.826$ & & $0.039 \pm 1.090$ & & $0.654 \pm 1.429$ & \\
\hline G5 & $3.400 \pm 0.826$ & \multirow{4}{*}{ G5-G8: 2.87} & $1.047 \pm 1.090$ & \multirow{4}{*}{ G5-G8: $\mathbf{0 . 6 5}$} & $0.293 \pm 1.429$ & \multirow{4}{*}{ G5-G8: $\mathbf{0 . 7 3}$} \\
\hline G6 & $1.809 \pm 0.826$ & & $1.288 \pm 1.090$ & & $0.493 \pm 1.429$ & \\
\hline G7 & $2.526 \pm 0.826$ & & $0.354 \pm 1.090$ & & $0.524 \pm 1.429$ & \\
\hline G8 & $3.762 \pm 0.826$ & & $-0.104 \pm 1.090$ & & $0.937 \pm 1.429$ & \\
\hline P1 & $1.905 \pm 0.791$ & \multirow{4}{*}{ P1-P4: 2.75} & $-1.272 \pm 1.043$ & \multirow{4}{*}{ P1-P4: -1.16 } & $1.045 \pm 1.368$ & \multirow{4}{*}{ P1-P4: 1.25} \\
\hline $\mathrm{P} 2$ & $2.226 \pm 0.876$ & & $-1.200 \pm 1.156$ & & $0.398 \pm 1.516$ & \\
\hline P3 & $3.282 \pm 0.826$ & & $-1.125 \pm 1.090$ & & $1.223 \pm 1.429$ & \\
\hline P4 & $3.638 \pm 0.826$ & & $-1.043 \pm 1.090$ & & $1.618 \pm 1.429$ & \\
\hline P5 & $2.823 \pm 0.826$ & \multirow{4}{*}{ P5-P8: 2.65} & $1.732 \pm 1.090$ & \multirow{4}{*}{ P5-P8: $\mathbf{0 . 2 7}$} & $-0.039 \pm 1.429$ & \multirow{4}{*}{ P5-P8: 0.43} \\
\hline P6 & $1.774 \pm 0.826$ & & $1.317 \pm 1.090$ & & $0.337 \pm 1.429$ & \\
\hline P7 & $2.303 \pm 0.826$ & & $-0.772 \pm 1.090$ & & $0.573 \pm 1.429$ & \\
\hline P8 & $3.686 \pm 0.826$ & & $-1.215 \pm 1.090$ & & $0.851 \pm 1.011$ & \\
\hline $\mathrm{C} 1$ & $1.831 \pm 0.826$ & \multirow{2}{*}{$\mathrm{C} 1, \mathrm{C} 2: \mathbf{2 . 1 5}$} & $0.305 \pm 1.090$ & \multirow{2}{*}{$\mathrm{C} 1, \mathrm{C} 2: \mathbf{0 . 0 3}$} & $-0.394 \pm 1.429$ & \multirow{2}{*}{$\mathrm{C} 1, \mathrm{C} 2: \mathbf{-} \mathbf{0 . 3 5}$} \\
\hline $\mathrm{C} 2$ & $2.478 \pm 0.826$ & & $-0.253 \pm 1.090$ & & $-0.302 \pm 1.429$ & \\
\hline
\end{tabular}



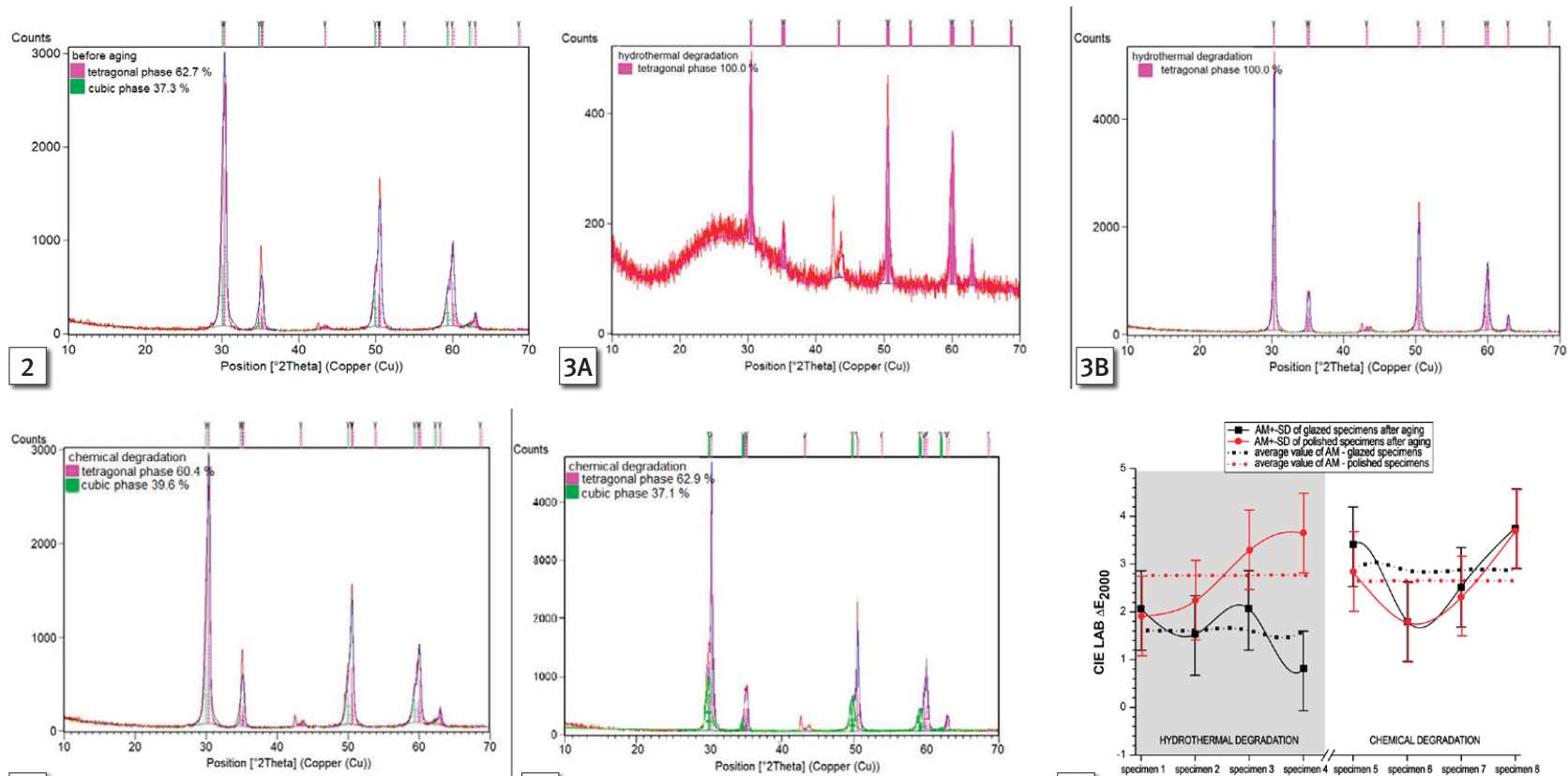

$4 \mathrm{~A}$

$4 B$
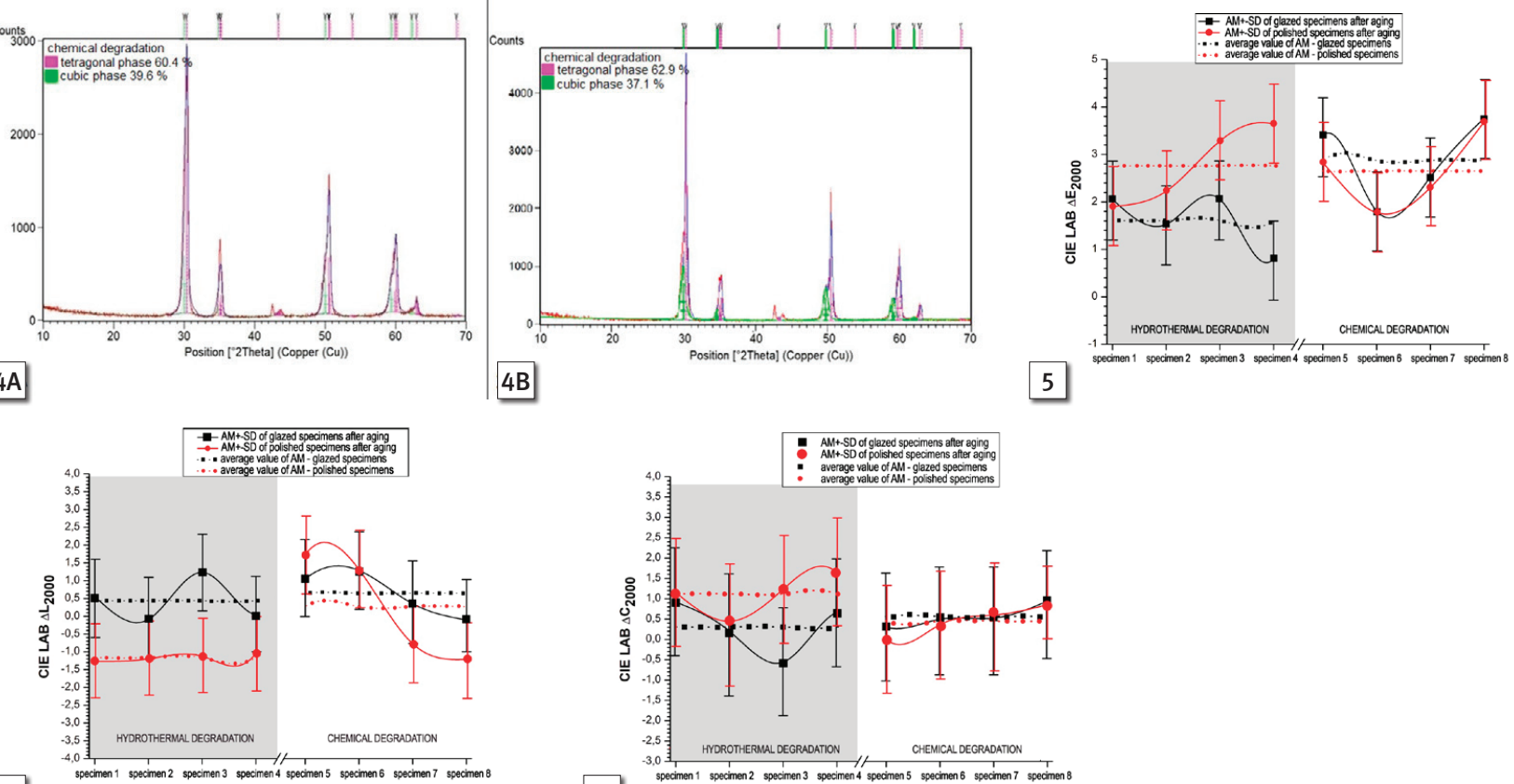

6

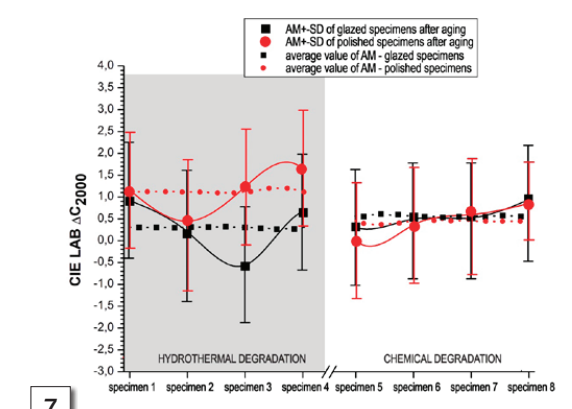

Figure $2 \mathrm{X}$-ray diffractometry of polished specimens $\mathrm{P} 1$ and $\mathrm{P} 5$ before aging.

Slika 2. Rendgenska difraktometrija poliranih uzoraka P1 i P5 prije starenja

Figure 3 X-ray diffractometry after hydrothermal degradation in an autoclave for glazed specimen G1 (3A) and polished specimen P1 (3B).

Slika 3. Rendgenska difraktometrija glaziranog uzorka G1 (3A) i poliranog uzorka P1 (3B) nakon hidrotermalne degradacije $u$ autoklavu

Figure $4 \mathrm{X}$-ray diffractometry after chemical degradation in a corrosive medium for glazed specimen G5 (4A) and polished specimen P5 (4B).

Slika 4. Rendgenska difraktometrija glaziranog uzorka G5 (4A) i poliranog uzorka P5 (4B) nakon kemijske degradacije u korozivnom mediju

Figure 5 Graphic display of CIE $\triangle E$ interval values $(A M \pm S D)$ after aging protocols on glazed and polished specimens.

Slika 5. Grafički prikaz intervala vrijednosti $C I E \triangle E(A S \pm S D)$ nakon protokola starenja za glazirane i polirane uzorke

Figure 6 Graphic display of $\mathrm{CIE} \Delta \mathrm{L}$ interval values $(\mathrm{AM} \pm \mathrm{SD})$ after aging protocols on glazed and polished specimens.

Slika 6. Grafički prikaz intervala vrijednosti $\mathrm{CIE} \Delta \mathrm{L}(\mathrm{AS} \pm \mathrm{SD})$ nakon protokola starenja za glazirane i polirane uzorke

Figure 7 Graphic display of CIE $\triangle C$ interval values $(A M \pm S D)$ after aging protocols on glazed and polished specimens.

Slika 7. Grafički prikaz intervala vrijednosti $\mathrm{CIE} \Delta \mathrm{C}(\mathrm{AS} \pm \mathrm{SD})$ nakon protokola starenja za glazirane i polirane uzorke

cal degradation in a corrosive medium (G5, P5) did not significantly change (Figure 4).

$\Delta \mathrm{E}, \Delta \mathrm{L}$ and $\Delta \mathrm{C}$ values were calculated using the $\mathrm{CIE} \Delta \mathrm{E}_{2000}$ formula and are presented as value intervals (arithmetical mean \pm standard deviation $(\mathrm{AM} \pm \mathrm{SD}))$ for all specimens (Table 2). Hydrothermal degradation resulted in a major color change in polished specimens (P1-P4) $\left(\Delta \mathrm{E}_{\text {avg }}=2.75\right)$ and a minor color change in glazed specimens (Grg 1-G4) $\left(\Delta \mathrm{E}_{\text {avg }}=1.64\right)$, but the latter change was significantly minor in comparison with other subgroups (G5-G8, P1-P4, P5-P8) (Tables 2 and 3). The chemical degradation of polished specimens (P5-P8) led to an average color change of $\Delta \mathrm{E}_{\text {avg }}=2.65$, while the same protocol caused a somewhat greater color change of $\Delta \mathrm{E}_{\text {avg }}=2.87$ in glazed specimens (G5-G8) (Tables 2
Vrijednosti $\Delta \mathrm{E}, \Delta \mathrm{L}$ i $\Delta \mathrm{C}$ dobivene su izračunom prema formuli $\mathrm{CIE} \Delta \mathrm{E}_{2000}$ i prikazane u obliku intervala vrijednosti [aritmetička sredina \pm standardna devijacija $(\mathrm{AS} \pm \mathrm{SD})$ ] za sve uzorke (tablica 2.). Hidrotermalnom degradacijom ostvarila se veća kolorna promjena poliranih uzoraka $(\mathrm{P} 1-\mathrm{P} 4)\left(\Delta \mathrm{E}_{\text {cred }}\right.$ $=2,75)$ te manja glaziranih uzoraka $(\mathrm{G} 1-\mathrm{G} 4)\left(\Delta \mathrm{E}_{\text {sred }}=1,64\right)$ koja je ujedno statistički značajno manja od uzoraka u ostalim podskupinama (G5 - G8, P1 - P4, P5 - P8) (tablice 2. i 3.). Kemijskom degradacijom poliranih uzoraka (P5 - P8) nastala je kolorna promjena $\Delta \mathrm{E}_{\text {sred }}=2,65$, a glazirani uzorci pri istom protokolu (G5 - G8) ostvarili su nešto veću kolornu promjenu $\Delta \mathrm{E}_{\text {sred }}=2,87$ (tablice 2. i 3.). Kontrolni uzorci ostvarili su kolornu promjenu $\Delta \mathrm{E}_{\text {sred }}=2,15$ koja se statistički značajno ne razlikuje od uzoraka u drugim podskupina- 
and 3). The change of color of $\Delta$ Eavg $=2.15$ occurred in control specimens which, from a statistical point of view, did not differ significantly from the specimens in other subgroups (Tables 2 and 3). In the analysis of obtained color changes, a somewhat more pronounced difference in the component defining the lightness of the specimens was observed. In polished specimens (P1-P4), hydrothermal degradation brought about an average lightness change of $\Delta \mathrm{L}_{\text {avg }}=-1.16$, which was statistically much greater than in other subgroups (P5-P8, G1-G4, G5-G8) (Tables 2 and 3). Differences in chromaticity (variations between the values of $\mathrm{a}^{*}$ and $\mathrm{b}^{*}$ coordinates) were less pronounced than differences in lightness $\left(\mathrm{L}^{*}\right)$. Such deviations primarily occurred along the $\mathrm{b}^{*}$ coordinate (value increase). No statistically significant differences in chromaticity $\Delta \mathrm{C}$ among the subgroups were recorded (Tables 2 and 3). Figures 5, 6 and 7 graphically show all resulting deviations in the coloration of specimens subjected to experimental protocols, along with deviations in lightness and chromaticity. A significant color change $\Delta \mathrm{E}$ in specimens G5-G8, $\mathrm{P} 1-\mathrm{P} 4$ and $\mathrm{P} 5-\mathrm{P} 8$ is visible in the graphs. Parameters $\Delta \mathrm{L}$ and $\triangle \mathrm{C}$ underwent a more significant change in subgroup P1-P4, although the change in parameter $\Delta \mathrm{C}$ has not been statistically significant.

The value intervals ( $\mathrm{AM} \pm \mathrm{SD}$ ) for the translucency parameter (TP) of all specimens before $\left(\mathrm{TP}_{0}\right)$ and after $\left(\mathrm{TP}_{1}\right)$ experimental protocols displayed a homogeneity in results without statistical significance (Table 4). Hydrothermal degradation in an autoclave and chemical degradation in a corrosive medium did not have a statistically significant effect on the translucency parameter in tested subgroups, although a decrease in TP $(\Delta \mathrm{TP})$ was greater in polished $(\Delta \mathrm{TP}$ avg from -0.96 to -0.5$)$ than in glazed specimens $\left(\Delta \mathrm{TP}_{\text {avg }}\right.$ from -0.42 to -0.07 ) (Table 4).

\section{Discussion}

Long-term conditions inside the oral cavity are simulated by subjecting samples to hydrothermal degradation in an autoclave, while chemical degradation in a corrosive medium (ISO 6872:2015) is a way of testing the resistance of materials to chemicals $(18,19)$. Acetic acid, applied in accordance with the standard, has a $\mathrm{pH}$ value $(\mathrm{pH} 2.49)$ very similar to the values inside the plaque and in the oral cavity when acidic food and drinks are consumed $(18,19)$. Hydrothermal degradation in an autoclave effectuated a change in the microstructure of both specimen groups (G1-G8, P1-P8), i.e. grains in the cubic crystal lattice were fully transformed into a tetragonal crystal lattice (Figure 3), but a tetragonal-tomonoclinic transformation did not occur. Likewise, Muñoz et al. did not prove the occurrence of a monoclinic phase, but their study of monolithic zirconia with a tetragonal-cubic microstructure found that hydrothermal degradation triggered an increase in the share of the cubic phase (20). Kolakarnprasert et al. also did not prove the presence of a monoclinic phase in the material when subjecting specimens to a temperature of $120^{\circ} \mathrm{C}$ over a 12 -hour period (17). The microstruc- ma (tablice 2. i 3.). Analizom ostvarenih kolornih promjena uočena je nešto izraženija razlika u komponenti koja definira svjetlinu uzoraka. Hidrotermalna degradacija prouzročila je na poliranim uzorcima $(\mathrm{P} 1-\mathrm{P} 4)$ prosječnu promjenu svjetline $\Delta \mathrm{L}_{\text {sred }}=-1,16$ koja je statistički značajno veća od uzoraka u ostalim podskupinama (P5 - P8, G1 - G4, G5 - G8) (tablice 2. i3.). Razlike u kromatičnosti (varijacije između vrijednosti koordinata $\mathrm{a}^{*} \mathrm{i} \mathrm{b}^{*}$ ) manje su izražene u odnosu prema razlikama u svjetlini $\left(\mathrm{L}^{*}\right)$. Tako se površinskom obradom glaziranjem uz hidrotermalnu degradaciju (G1 - G4) postigla prosječna promjena u kromatičnosti $\Delta \mathrm{C}_{\text {sred }}=0,28$, a kemijskom degradacijom $(\mathrm{G} 5-\mathrm{G} 8)$ dobiveno je veće odstupanje $\left(\Delta \mathrm{C}_{\text {sred }}\right.$ $=0,73$ ) (tablice 2. i 3.). Takva odstupanja uglavnom se ostvaruju po koordinati $b^{*}$ (povećava se njihova vrijednost). Porast po koordinati $b^{*}$ zabilježen je i na poliranim uzorcima, osobito u podskupini izloženoj hidrotermalnoj degradaciji (P1 P4) $\left(\Delta \mathrm{C}_{\text {sred }}=1,25\right)$ (tablice 2. i 3.). Između podskupina nisu zabilježene statistički značajne razlike u kromatičnosti $\Delta \mathrm{C}$ (tablice 2. i 3.). Na slikama 5., 6. i 7. grafički su prikazana ukupno nastala odstupanja u obojenju uzoraka izloženih eksperimentalnim protokolima te njihova odstupanja u svjetlini i kromatičnosti. Na grafovima se vidi značajna kolorna promjena $\Delta$ E na uzorcima G5 - G8, P1 - P4 te P5 - P8. Parametri $\Delta \mathrm{L}$ i $\Delta \mathrm{C}$ značajnije su promijenjeni u podskupini P1 $\mathrm{P} 4$, iako promjena u parametru $\Delta \mathrm{C}$ nije statistički značajna.

Intervali vrijednosti $(A S \pm S D)$ parametra translucencije (TP) svih uzoraka prije $\left(\mathrm{TP}_{0}\right)\left(\mathrm{TP}_{1}\right)$ eksperimentalnih protokola i poslije njih pokazuju ujednačene rezultate bez statističke značajnosti (tablica 4.). Hidrotermalna degradacija u autoklavu i kemijska degradacija u korozivnom mediju nisu statistički značajno utjecale na parametar translucencije unutar ispitivanih podskupina, iako je promjena TP-a $(\Delta \mathrm{TP})$ $\mathrm{u}$ obliku smanjenja veća na poliranim uzorcima $\left(\Delta \mathrm{TP}_{\text {sred }}\right.$ od $-0,96$ do $-0,5) \mathrm{u}$ odnosu prema glaziranima $\left(\Delta \mathrm{TP}_{\text {sred }}\right.$ od $-0,42$ do -0,07) (tablica 4.).

\section{Rasprava}

Izlaganjem materijala hidrotermalnoj degradaciji u autoklavu simuliraju se uvjeti u usnoj šuplijini tijekom duljeg razdoblja, a kemijska degradacija u korozivnom mediju (ISO 6872:2015) način je ispitivanja kemijske postojanosti materijala $(18,19)$. Octena kiselina primijenjena prema standardu ima $\mathrm{pH}$ vrijednost vrlo sličnu ( $\mathrm{pH} 2,49)$ uvjetima u usnoj šupljini koji nastaju pri konzumaciji hrane i pića niskih $\mathrm{pH}$ vrijednosti, te $\mathrm{pH}$ vrijednosti unutar plaka $(18,19)$. Tijekom hidrotermalne degradacije u autoklavu dogodila se promjena u mikrostrukturi obiju skupina uzoraka, odnosno zrna kubične kristalne rešetke potpuno su transformirana u tetragonsku kristalnu rešetku (slika 3.), ali se tetragonsko-monoklinska transformacija nije dogodila, što navodi na zaključak da je prva hipoteza ovog istraživanja djelomično prihvaćena. Muñoz i suradnici u istraživanju monolitnoga cirkonijeva oksida tetragonsko-kubične mikrostrukture također nisu dokazali pojavu monoklinske faze, ali se u njihovoj studiji tijekom hidrotermalne degradacije pojavio veći udjel kubične u odnosu prema tetragonskoj fazi (20). Kolakarnprasert i suradnici pri izlaganju uzoraka temperaturi od $120^{\circ} \mathrm{C}$ tijekom 12 
ture of specimens subjected to corrosive degradation did not change, i.e. the ratio between cubic and tetragonal phase remained almost unchanged from the start of the present research (Figure 4). These results led to conclusions that the first hypothesis of this research is partially accepted. According to Kolakarnprasert, translucent zirconia ceramics owes its stable tetragonal-cubic structure to its share of yttrium oxide $-\mathrm{Y}_{2} \mathrm{O}_{3}$ (approximately $5 \mathrm{~mol} \%$ ), which is larger than in previous generations of the same material (2-3 mol \%) (17). A combined tetragonal-cubic structure affects the mechanical and optical properties of the material. According to Sulaiman et al. (21-23) and Zhang et al. $(13,16)$, augmented dimensions of cubic crystals make materials with such a structure more fragile, but also more translucent, as dispersion is abated, while transmission though material is amplified vis-à-vis the previous generations. Yttrium oxide has an impact on mechanical properties; its share has been increased, while the share of aluminum oxide crystals, which contributed to superior mechanical properties of previous generations, has been reduced (24-26).

Colorimetry is a scientific discipline dealing with color and surface measurement as well as the precise presentation of those measurements in various color spaces employed for coloring delineation $(27,28)$. At the moment, the most commonly utilized color space is the three-dimensional CIE LAB, which, apart from high-quality visualization, it also enables easier definition of color deviations between two shades (2729). In order to measure color differences on specimens before and after aging protocols as well as intergroup differences, a reflex spectrophotometer was employed. This device is used in graphic industry and would normally not be suitable for intraoral color determination in dental medicine. However, taking into account the fact that this was an in-vitro study in which disc-shaped specimens were employed, a device for measuring color parameters on flat surfaces was deemed to be the most suitable choice as it provided objective results and comparable numerical values, while the effect of the human factor, i.e. subjective perception, was eliminated (27-31). In this research, the color change, expressed as the average value of arithmetical means $\Delta \mathrm{E}_{\text {avg }}$, in glazed specimens exposed to hydrothermal degradation in an autoclave (G1-G4) exhibited clinically more acceptable values $\left(\Delta \mathrm{E}_{2 \mathrm{vg}}=1.64\right)$, which has been confirmed in prior studies $(15,27,28,31)$. The mean values $\Delta \mathrm{E}$ in the subgroup subjected to chemical degradation (G5-G8) in a corrosive medium (the average value of arithmetical means being $\Delta \mathrm{E}_{\text {avg }}=2.87$ ) were significantly higher than in subgroup exposed to hydrothermal degradation (Tables 2 and 3). Due to the stability of phase composition, i.e. the absence of a monoclinic phase, this color change may be attributed to the dissolving of glaze in an aggressive medium, which in turn affects the perception of optical properties (32-34). An amorphous material, glaze, is not resistant to aggressive external influences nor is it chemically stable (33-35). In an aggressive medium, surface ions in the glaze perish, which leads to irregularities (secondary porosity) that augment roughness - a finding that corresponds to the findings of other authors (32-34). It is important to emphasize that long-term color changes on restorations in the oral cav- sati u vodi također nisu dokazali monoklinsku fazu u materijalu (17). Na uzorcima izloženima korozijskoj degradaciji, mikrostruktura je ostala gotovo nepromijenjena, odnosno koegzistirale su kubična i tetragonska faza u gotovo jednakom postotku kao na početku istraživanja (slika 4.). Prema Kolakarnprasertu, translucentna cirkonij-oksidna keramika ima stabilnu tetragonsko-kubičnu strukturu zahvaljujući većem udjelu itrijeva oksida $-\mathrm{Y}_{2} \mathrm{O}_{3}$ (oko $12 \%$ molekularnog udjela) u odnosu prema prijašnjim generacijama materijala (2 - $3 \%$ molekularnog udjela) (17). Kombinirana tetragonskokubična struktura utječe na mehanička i optička svojstva materijala. Prema Sulaimanu i suradnicima $(21-23)$ te Zhangu i suradnicima $(13,16)$, materijali s takvom strukturom krhkiji su zbog većih dimenzija kubičnih kristala, ali i translucentniji zbog manjeg rasapa svjetlosti, a veće transmisije kroz materijal u odnosu prema prethodnim generacijama. Na mehanička svojstva utječe itrijev oksid čiji je udio povećan, a reducirani su kristali aluminijeva oksida koji su pridonosili boljim mehaničkim svojstvima prethodnih generacija materijala $(24-26)$.

Kolorimetrija kao znanstvena disciplina bavi se metrikom boja i podloga te njezinim točnim prikazivanjem u različitim kolornim prostorima za opis obojenja $(27,28)$. Trenutačno najčešće korišten kolorni prostor jest trodimenzionalni CIE LAB koji, uz kvalitetnu vizualizaciju, može lako definirati i kolorno odstupanje između dvaju tonova (27 - 29). Za mjerenje kolornih razlika na uzorcima prije protokola starenja i poslije njega te razlika između skupina primijenjen je refleksijski spektrofotometar koji se inače upotrebljava u grafičkoj industriji i ne bi bio prikladan za odredivanje boje u dentalnoj medicini koje se provodi intraoralno. No s obzirom na činjenicu da se u ovom slučaju radilo o istraživanju in vitro u kojemu su korišteni uzorci u obliku pločica, takav uređaj za mjerenje parametara boje ravnih površina bio je pogodan. Korištenje spektrofotometara najpogodnije je radi objektivizacije rezultata, dobivanja numeričkih vrijednosti koje se mogu usporedivati i eliminacije utjecaja ljudskog čimbenika, odnosno subjektivnog dojma $(27-31)$. U ovom istraživanju kolorna promjena izražena prosječnom vrijednošću aritmetičkih sredina $\Delta \mathrm{E}$ kod glaziranih uzoraka izloženih hidrotermalnoj degradaciji $\left(\mathrm{G} 1\right.$ - G4) u autoklavu $\left(\Delta \mathrm{E}_{\text {sred }}=1,64\right)$ pokazuje klinički prihvatljive vrijednosti, što je potvrđeno i u drugim istraživanjima $(15,27,28,31)$, iako srednje vrijednosti $\Delta \mathrm{E}$ u skupini izloženoj kemijskoj degradaciji (G5-G8) u korozivnom mediju (s prosječnom vrijednošću aritmetičkih sredina $\Delta \mathrm{E}_{\text {sred }}=$ 2,87 ) pokazuju statistički značajno veće vrijednosti (tablice 2. i 3.). Zbog stabilnosti faznog sastava i odsutnosti monoklinske faze ta se kolorna promjena može pripisati otapanju glazure u agresivnom mediju, što utječe na percepciju optičkih svojstava $(32-34)$. Glazura kao amorfni materijal nije otporna na agresivne vanjske utjecaje, a nije ni kemijski stabilna $(33-35)$. U agresivnom mediju iz glazure se gube površinski ioni, pa se stvaraju nepravilnosti (sekundarni porozitet) koje povećavaju hrapavost, što je u skladu $s$ istraživanjima drugih autora $(32-34)$. Važno je istaknuti da nastale kolorne promjene na nadomjestcima u usnoj šupljini tijekom godina vjerojatno ne bi bile vidljive, pogoto- 
ity would not be noticeable, but the following question arises: what would have happened to the material if, in addition to permanent moisture as well as changing temperature and $\mathrm{pH}$ values, it had been also exposed to discoloration-inducing beverages and oral hygiene product? Haralur et al. (35) offered the evidence that the greatest color change occurs af- vo u uvjetima stalne vlažnosti, iako se postavlja pitanje što bi bilo s materijalom koji bi, uz promjene temperature, stalne vlažnosti i promjene $\mathrm{pH}$, bio izložen raznim potencijalnim diskolorirajućim napitcima i sredstvima oralne higijene. Haralur i suradnici dokazuju najveću kolornu promjenu na monolitnom cirkonijevu oksidu u odnosu prema litij-di-
Table 3 Statistical analysis of $\Delta E, \Delta \mathrm{L}$ and $\Delta \mathrm{C}$ parameters among specimen subgroups including a display of significance (One-way ANOVA comparison, $\mathrm{P}<0.05) . \mathrm{G}$ - glazed specimens, $\mathrm{P}$ - polished specimens, $\mathrm{H}-$ hydrothermal aging, $\mathrm{C}$ - chemical aging, $\mathrm{C}$ control specimens.

Tablica 3. Statistička analiza parametara $\Delta \mathrm{E}, \Delta \mathrm{L} \mathrm{i}$ $\Delta$ C između podskupina uzoraka, uz prikaz statističke značajnosti (jednosmjerna ANOVA, P $<0,05)$. G - glazirani uzroci, $\mathrm{P}$ - polirani uzorci, $\mathrm{H}$ - hidrotermalna degradacija, $\mathrm{C}$ - kemijska degradacija, $C$ - kontrolni uzorci

\begin{tabular}{|c|c|c|c|}
\hline $\begin{array}{l}\text { Combinations between } \\
\text { subgroups } \bullet \text { Kombinacije } \\
\text { između podskupina }\end{array}$ & $\mathbf{P}(\Delta \mathrm{E})$ & $\mathbf{P}(\Delta \mathrm{L})$ & $\mathbf{P}(\Delta \mathrm{C})$ \\
\hline G-H vs G-C & 0.002 & 0.697 & 0.66 \\
\hline G-H vs P-H & 0.007 & 0.036 & 0.197 \\
\hline G-H vs P-C & 0.03 & 0.725 & 0.787 \\
\hline G-H vs C & 0.163 & 0.44 & 0.347 \\
\hline G-C vs G-H & 0.002 & 0.697 & 0.66 \\
\hline G-C vs P-H & 0.779 & 0.0005 & 0.483 \\
\hline $\mathrm{G}-\mathrm{C}$ vs $\mathrm{P}-\mathrm{C}$ & 0.65 & 0.572 & 0.855 \\
\hline G-C vs $\mathrm{C}$ & 0.153 & 0.408 & 0.321 \\
\hline $\mathrm{P}-\mathrm{H}$ vs $\mathrm{G}-\mathrm{H}$ & 0.007 & 0.036 & 0.197 \\
\hline P-H vs G-C & 0.779 & 0.0005 & 0.499 \\
\hline $\mathrm{P}-\mathrm{H}$ vs $\mathrm{P}-\mathrm{C}$ & 0.847 & 0.024 & 0.344 \\
\hline $\mathrm{P}-\mathrm{H}$ vs $\mathrm{C}$ & 0.261 & 0.065 & 0.05 \\
\hline $\mathrm{P}-\mathrm{C}$ vs G-H & 0.029 & 0.725 & 0.787 \\
\hline $\mathrm{P}-\mathrm{C}$ vs $\mathrm{G}-\mathrm{C}$ & 0.653 & 0.572 & 0.855 \\
\hline $\mathrm{P}-\mathrm{C}$ vs $\mathrm{P}-\mathrm{H}$ & 0.847 & 0.024 & 0.339 \\
\hline $\mathrm{P}-\mathrm{C}$ vs $\mathrm{C}$ & 0.297 & 0.794 & 0.261 \\
\hline C vs G-H & 0.163 & 0.44 & 0.347 \\
\hline C vs G-C & 0.153 & 0.408 & 0.321 \\
\hline $\mathrm{C}$ vs P-H & 0.261 & 0.065 & 0.05 \\
\hline $\mathrm{C}$ vs $\mathrm{P}-\mathrm{C}$ & 0.297 & 0.794 & 0.261 \\
\hline
\end{tabular}

Table 4 Value intervals for translucency parameter before (TP) and after (TP, aging protocols with average change of arithmetical means $\left(\Delta \mathrm{TP}_{\text {avg }}\right.$ ) of glazed (G1-G8), polished (P1-P8) and control (C1, C2) specimens (Tukey test with a 95\% confidence interval, $\left.\mathrm{P}<0.05\right)$.

Tablica 4. Interval vrijednosti parametra translucencije prije (TP $)$ protokola starenja i nakon toga postupka (TP $)_{1}$ s prikazom srednjih vrijednosti aritmetičkih sredina $\left(\Delta \mathrm{TP}_{\text {seed }}\right)$ glaziranih (G1 -G8), poliranih (P1 - P8) i kontrolnih (C1, C2) uzoraka (Tukeyjev test s 95-postotnim intervalom pouzdanosti, $\mathrm{P}<0,05)$.

\begin{tabular}{|c|c|c|c|c|}
\hline Specimen • Uzorak & $\begin{array}{c}\mathrm{TP}_{0} \\
(\mathrm{AM} \pm \stackrel{\mathrm{SD}}{ }) \\
(\mathrm{AS} \pm \mathrm{SD})\end{array}$ & $\begin{array}{c}\mathrm{TP}_{1} \\
(\mathrm{AM} \pm \mathrm{SD}) \\
(\mathrm{AS} \pm \mathrm{SD})\end{array}$ & $\begin{array}{c}\Delta \mathrm{TP}_{\text {avg }} \text { (average change of } \\
\text { arithmetical means) } \bullet \Delta \mathrm{TP}_{\text {sred }} \\
\text { (srednja vrijednost aritmetickkih } \\
\text { sredina) }\end{array}$ & $\mathbf{P}$ \\
\hline G1 & $7.63 \pm 0.666$ & $7.617 \pm 0.666$ & \multirow{4}{*}{-0.07} & \multirow{4}{*}{1.000} \\
\hline G2 & $7.784 \pm 0.738$ & $7.774 \pm 0.738$ & & \\
\hline G3 & $7.392 \pm 0.695$ & $7.142 \pm 0.695$ & & \\
\hline G4 & $6.849 \pm 0.695$ & $6.84 \pm 0.695$ & & \\
\hline G5 & $7.842 \pm 0.695$ & $7.12 \pm 0.695$ & \multirow{4}{*}{-0.42} & \multirow{4}{*}{1.000} \\
\hline G6 & $7.477 \pm 0.695$ & $7.25 \pm 0.695$ & & \\
\hline G7 & $7.45 \pm 0.695$ & $7.116 \pm 0.695$ & & \\
\hline G8 & $7.365 \pm 0.695$ & $6.912 \pm 0.695$ & & \\
\hline P1 & $7.391 \pm 0.675$ & $7.254 \pm 0.675$ & \multirow{4}{*}{-0.93} & \multirow{4}{*}{0.29} \\
\hline $\mathrm{P} 2$ & $8.044 \pm 0.748$ & $6.661 \pm 0.748$ & & \\
\hline P3 & $8.296 \pm 0.705$ & $7.239 \pm 0.705$ & & \\
\hline $\mathrm{P} 4$ & $7.837 \pm 0.705$ & $6.683 \pm 0.705$ & & \\
\hline $\mathrm{P} 5$ & $8.007 \pm 0.705$ & $7.317 \pm 0.705$ & \multirow{4}{*}{-0.5} & \multirow{4}{*}{0.403} \\
\hline P6 & $7.501 \pm 0.705$ & $6.896 \pm 0.705$ & & \\
\hline P7 & $7.483 \pm 0.705$ & $7.736 \pm 0.705$ & & \\
\hline P8 & $8.021 \pm 0.705$ & $7.031 \pm 0.705$ & & \\
\hline $\mathrm{C} 1$ & $8.027 \pm 0.705$ & $7.981 \pm 0.705$ & \multirow{2}{*}{-0.16} & \multirow{2}{*}{1.000} \\
\hline $\mathrm{C} 2$ & $7.651 \pm 0.705$ & $7.374 \pm 0.705$ & & \\
\hline
\end{tabular}


ter a thermo-cycling process as well as immersion in coffee, tea and chlorhexidine in monolithic zirconia, as opposed to lithium-disilicate ceramics and bilayer zirconia systems. Kurt et al. (36) have proven the direct connection between color changes on monolithic zirconia and the aging process that the material is subjected to; this phenomenon is explained by the direct exposure of monolithic surface of zirconia to a watery milieu, i.e. saliva, which stimulates the LTD of crystals on the surface of the materials, while the consequential expansion of grains in the monoclinic phase results in micro-cracks and an increased roughness of the surface, which has repercussions on the extent of the color change. Lithium-disilicate ceramics demonstrate greater color stability, i.e. their $\Delta \mathrm{E}$ change is smaller than in monolithic zirconia (36). In this research, polished specimens demonstrated $\Delta \mathrm{E}$ color differences that were within the scope of clinically acceptable values, but were also significantly greater than in glazed specimens aged in an autoclave (average values of arithmetical means $\Delta \mathrm{E}_{\text {avg }}$ in polished specimens P1-P4: $\Delta \mathrm{E}_{\text {avg }}=2.75$; P5-P8: $\left.\Delta \mathrm{E}_{\text {avg }}=2.65\right)$ (Tables 2 and 3). There were no statistically significant differences in $\Delta \mathrm{E}$ values among glazed specimens subjected to chemical degradation (G5-G8) and between both subgroups of polished specimens (P1-P4, P5-P8), i.e. the ensuing color changes were similar (Table 3 ). The impact of hydrothermal degradation in an autoclave on glazed specimens (G1-G4) was deflated by a protective coating on the surface (glaze), which, unlike in specimens without a protective coating, inhibited the penetration of water into the material, i.e. the degradation of the material. This assertion is confirmed by Palla et al., who have affirmed that the infiltration of water through the surface of a non-glazed glass ceramic causes the structure to disintegrate (37). Camposilvan et al. have suggested to glazie all zirconia restorations in order to inhibit the impact of the hydrothermal aging protocol on the surface of the material (38). Previous studies have also shown that the quality of the final surface of the restoration has an impact on color stability, i.e. glazed and highly polished surfaces manifest better color stability in the long run (39). In the current study, greater changes $\Delta \mathrm{L}$ and $\Delta \mathrm{C}$ were observed in polished specimens subjected to hydrothermal degradation (P1-P4), followed by glazed specimens subjected to chemical degradation (G5-G8) (Tables 2 and 3). An increase of chromaticity along the $\mathrm{b}^{*}$ co-ordinate in all subgroups, in varying degrees, indicated light yellowing of specimens after aging protocols, which did not occur in control specimens not subjected to experimental protocols (Table 3 ). A decrease in the lightness of polished specimens aged in an autoclave (P1-P4), which was statistically significant when compared to other subgroups (P5-P8, G1-G4, G5-G8), resulted in greater color saturation, i.e. greater $\Delta \mathrm{C}$ change after aging in an autoclave $\left(\Delta \mathrm{L}_{\text {avg }}=-1.16, \Delta \mathrm{C}_{\text {avg }}=1.25\right)$, although this values were not statistically significant compared with other subgroups (Table 3). These data are in line with a study by Ledić (40), in which a decrease in the lightness of lithium-disilicate ceramic specimens consequently led to an increase in color saturation. Glazed specimen G8 and polished specimens P4 and $\mathrm{P} 8$ manifested mean $\Delta \mathrm{E}$ values marginally greater than those that are clinically acceptable $(15,27,31,41)$ (Table 2$)$. silikatnoj keramici i dvoslojnim cirkonij-oksidnim sustavima nakon imerzije u kavi, čaju i klorheksidinu te izlaganju termocikličkom procesu (35). Kurt i suradnici dokazali su da su kolorne promjene na monolitnoj cirkonij-oksidnoj keramici u izravnoj vezi s izlaganjem materijala procesu starenja i tu pojavu objašnjavaju direktnom izloženošću površine monolitne cirkonij-oksidne keramike vodenom miljeu, odnosno slini čime se potiče LTD kristala na površini materijala, a posljedična ekspanzija zrna monoklinske faze dovodi do mikropukotina i povećanja hrapavosti površine, što ima reperkusije na veličinu kolorne promjene (36). Litij-disilikatna keramika pokazala je veću kolornu stabilnost, odnosno manju promjenu $\Delta \mathrm{E}$ u usporedbi $s$ monolitnom cirkonijoksidnom keramikom (36). U ovom istraživanju polirani uzorci pokazuju kolorne razlike $\Delta \mathrm{E}$ koje su također u sklopu klinički prihvatljivih vrijednosti, iako su one statistički značajno veće u odnosu prema glaziranim uzorcima koji su starjeli u autoklavu (prosječne vrijednosti aritmetičkih sredina $\Delta \mathrm{E}$ kod poliranih uzoraka P1 - P4: $\Delta \mathrm{E}_{\text {sred }}=2,75$; P5 P8: $\left.\Delta \mathrm{E}_{\text {sred }}=2,65\right)$ (tablice 2. i 3.). Između glaziranih uzoraka izloženih kemijskoj degradaciji (G5 - G8) te u objema podskupinama poliranih uzoraka (P1 - P4, P5 - P8) nema statistički značajne razlike u vrijednosti $\Delta \mathrm{E}$, odnosno nastala je slična kolorna promjena (tablica 3.). Utjecaj hidrotermalne degradacije u autoklavu kod glaziranih uzoraka (G1 - G4) smanjen je zbog zaštitne prevlake na površini (glazure), čime se bilo kakva penetracija vode u materijal, odnosno degradacija osnovnog materijala neće događati, za razliku od uzoraka koji nemaju zaštitnu prevlaku. Tu tvrdnju potvrđuju Palla i suradnici koji su dokazali da se kroz površinu neglaziranoga staklokeramičkoga nadomjestka infiltrira voda u materijal, što rezultira dezintegracijom strukture (37). Camposilvan i suradnici sugeriraju nanošenje glazure na sve nadomjestke cirkonij-oksidne keramike kako bi se spriječio utjecaj hidrotermalnog protokola starenja na površinu materijala (38). $\mathrm{U}$ dosadašnjim studijama također je istaknuto da kvaliteta površine završenog nadomjestka utječe na stabilnost boje, odnosno da glazirane površine, kao i visokopolirane, znače dugoročno bolju stabilnost boje (39). Rezultati ove studije pokazuju da su veće promjene $\Delta \mathrm{L}$ i $\Delta \mathrm{C}$ zamijećene na poliranim uzorcima pri hidrotermalnoj degradaciji (P1 - P4), a slijede ih glazirani uzorci izloženi kemijskoj degradaciji (G5 - G8) (tablice 2. i 3.). Porast kromatičnosti po koordinati b* u većoj ili manjoj mjeri u svim podskupinama znači lagano žućenje uzoraka nakon protokola starenja koje se nije pojavilo na kontrolnim uzorcima zato što nisu bili izloženi eksperimentalnim protokolima (tablica 3.). Pad svjetline poliranih uzoraka P1 - P4, koji je ujedno statistički značajan u odnosu prema uzorku ostalih podskupina (P5 - P8, G1 - G4, G5 - G8), ima kao posljedicu veću zasićenost bojom, odnosno veću promjenu $\Delta \mathrm{C}\left(\Delta \mathrm{L}_{\text {sred }}=-1,12, \Delta \mathrm{C}_{\text {sred }}=1,25\right)$ pri starenju $\mathrm{u}$ autoklavu, iako bez statističke značajnosti u usporedbi $s$ ostalim podskupinama (tablica 3.). To je u skladu s istraživanjem K. Ledić u kojemu su uzorci litijeve disilikatne keramike $s$ većim smanjenjem svjetline pokazali posljedičnu veću zasićenost bojom (40). Glazirani uzorak G8 i polirani uzorci P4 i P8 pokazuju granično veće vrijednosti $\Delta \mathrm{E}$ od klinički prihvatljive granice $(15,27,31,41)$ (tablica 2.). 
When discussing optical parameters of the tested materi$\mathrm{al}$, it has to be taken into account that the material is multilayered - it contains four layers that mutually differ in lightness and color saturation, i.e. the degree of transmission through the material. The material was layered to obtain a faithful reproduction of optical properties in a natural tooth (from a zone with less lightness and more saturation - corresponding to the cervical region - to a zone with more lightness and less saturation of color, in this case: A shade in the classical shade guide). Ueda et al. (42) have pointed out that light transmits through all four layers in multilayered monolithic zirconia differently, meaning that the layers have diverging optical properties. This fact may be of significance for these materials and would make the second hypothesis acceptable as longterm color changes on the material in the conditions of the oral cavity would be less discernible, especially if the restoration were to be glazed and the impact of the milieu in the oral cavity thus diminished. This part of the research could be supplemented and more insight into the color stability of this material could be acquired by immersing specimens into discoloration-inducing solutions of varying temperature and $\mathrm{pH}$ values while also conducting the experimental protocols here described; this is a subject for potential future research.

Speaking of optical properties of the material, one of the most important properties for expressing similarity with dental hard tissue and the factor affecting the choice of materials in fixed prosthodontic therapy is translucency (15). In the results of this study, the translucency values, as expressed through the translucency parameter (TP), were over 6.8 , but under 8.3 at the start of the study, with specimen thickness being $1.5 \mathrm{~mm} \pm 5 \%$. At the end of the study, the translucency values were over 6.6., but under 8 ; however, these differences were not statistically significant (Table 4). The translucency parameter did not change significantly following the aging protocol, which affirms the third hypothesis. Other studies confirm similar findings $(36,43)$. Kurt et al. (36) demonstrated the translucency parameter stability of a Zirkonzahn Prettau $[Z Z]$ monolithic zirconia ceramics, which was unaffected by either the final surface treatment or aging protocols. In a study by Abdelbary et al. (44), the TP value was much greater $(\mathrm{TP}=16.12 \pm 0.75)$ in $0.5 \mathrm{~mm}$ thick InCoris TZI monolithic zirconia ceramic specimens, whereas the TP value of $1.2 \mathrm{~mm}$ thick specimens was $9.25 \pm 1.45$. In that study, TP values of $0.5 \mathrm{~mm}$ thick specimens significantly decreased after hydrothermal degradation in an autoclave at a temperature of $134^{\circ} \mathrm{C}$ and under the pressure of 2 bar over a five-hour period (from $16.12 \pm 0.75$ to $12.56 \pm 1.36$ ), unlike the TP values of $0.8 \mathrm{~mm}$ (from $13.67 \pm 1.21$ to $13.24 \pm 2.42$ ), $1 \mathrm{~mm}$ (from $11.49 \pm 0.95$ to $11.08 \pm 0.33$ ) and $1.2 \mathrm{~mm}$ (from $9.25 \pm$ 1.45 to $9.74 \pm 1.31$ ) thick specimens, which were not significantly impacted by aging in the autoclave (44). The thickness of the specimens in this study was $1.5 \mathrm{~mm} \pm 5 \%$, hence the $\mathrm{TP}$ values found here are comparable to the TP values found by Abdelbary et al. for corresponding material thickness. Results of other studies correlate with the results of this study, thus confirming the connection between specimen thickness and TP value (45-48). This phenomenon can be explained in the following manner: the thicker the specimen/restora-
Ono što se mora uzeti u obzir kada se govori o optičkim parametrima ispitivanog materijala jest da je riječ o materijalu s četirima različitim slojevima koji se uzajamno razlikuju po svjetlini i zasićenosti boje (multilayered), odnosno prema stupnju propuštanja svjetlosti kroz materijal. Materijal je slojevan kako bi se dobila što vjernija reprodukcija optičkih svojstava u odnosu prema prirodnom zubu (od manje svijetle - zasićenije zone koja bi predstavljala cervikalnu regiju, prema zonama veće svjetline - manje zasićenosti boje, u ovom slučaju boje A prema klasičnom ključu boja). Ueda i suradnici pokazali su da sva četiri sloja višeslojnog monolitnog cirkonijeva oksida različito propuštaju svjetlost, odnosno da imaju drukčija optička svojstva (42). Ta činjenica može biti značajna kod takvih materijala jer bi tijekom vremena nastale kolorne promjene u uvjetima usne šupljine, osobito ako bi se nadomjestak glazirao, pa time smanjio utjecaj miljea usne šupljine, čime bi se druga hipoteza mogla prihvatiti. Dopuna ovom dijelu istraživanja i bolje spoznaje o kolornoj stabilnosti toga materijala dobile bi se ulaganjem uzoraka u diskolorirajuće otopine različite temperature i $\mathrm{pH}$ vrijednosti, uz provedbu eksperimentalnih protokola, što može biti tema budućih istraživanja.

Govoreći o optičkim svojstvima materijala, jedno od najvažnijih kojim se najbolje može iskazati sličnost $s$ tvrdim zubnim tkivima te čimbenik koji utječe na odabir materijala koji će se koristiti u fiksnoprotetičkoj terapiji, jest translucencija (15). Rezultati ove studije pokazuju da su vrijednosti translucencije izražene parametrom translucencije TP-a veće od 6,8, a manje od 8,3 pri debljini uzoraka od $1,5 \mathrm{~mm} \pm 5 \%$ na početku istraživanja, odnosno veće od 6,6 , a manje od 8 na kraju istraživanja, ali te razlike nisu statistički značajne (tablica 4.). Parametar translucencije nije se značajno promijenio nakon protokola starenja, čime se potvrđuje treća hipoteza. Druga istraživanja potvrđuju rezultate ove studije (36, 43). Kurt i suradnici (36) pokazali su stabilnost parametra translucencije (TP) monolitne cirkonij-oksidne keramike Zirkonzahn Prettau [ZZ] na koju nije utjecala vrsta završne obrade površine, niti protokol starenja. U studiji Abdelbaryja i suradnika vrijednost TP-a bila je značajno veća ( $\mathrm{TP}=16,12$ $\pm 0,75$ ) kod uzoraka monolitnoga translucentnog cirkonija InCoris TZI debljine $0,5 \mathrm{~mm}$, a pri debljini od $1,2 \mathrm{~mm}$ vrijednost TP-a iznosila 9,25 $\pm 1,45$ (44). U toj studiji vrijednosti TP uzoraka debljine $0,5 \mathrm{~mm}$ značajno su se smanjile nakon hidrotermalne degradacije u autoklavu na $134{ }^{\circ} \mathrm{C}$, pri tlaku od 2 bara tijekom 5 sati (s 16,12 $\pm 0,75$ na $12,56 \pm$ 1,36), za razliku od vrijednosti TP uzoraka debljina $0,8 \mathrm{~mm}$ (s 13,67 $\pm 1,21$ na $13,24 \pm 2,42), 1 \mathrm{~mm}$ (s $11,49 \pm 0,95$ na $11,08 \pm 1,33)$ i $1,2 \mathrm{~mm}(\mathrm{~s} 9,25 \pm 1,45$ na $9,74 \pm 1,31)$ na koje starenje u autoklavu nije značajno utjecalo (44). U ovom istraživanju uzorci su bili debljine $1,5 \mathrm{~mm} \pm 5 \%$, čime bi se dobivene vrijednosti TP-a mogle usporediti $s$ rezultatima TP-a Abdelbaryja i suradnika za materijal te debljine. Rezultati drugih studija u korelaciji su s rezultatima iz ove studije te potvrđuju vezu debljine uzorka $s$ vrijednošću TP-a ( 45 - 48). Objašnjenje za tu pojavu bilo bi da se s većom debljinom uzorka, odnosno nadomjestka povećava količina svjetlosti koja se apsorbira i reflektira, odnosno slabija je transmisija kroz materijal zbog većeg broja zrna $(11,13)$ i veće 
tion, the greater the amount of absorbed and reflected light and the weaker the transmission through the material. This is caused by a greater number of grains $(11,13)$ and a larger grain boundary surface (49) that the light encounters. When a specimen is thinner, transmission is stronger (45-48). However, it is important to stress the need of minimal material thickness that ensures an adequate degree of translucency and resistance to fractures $(12,43)$. Although changes in the translucency parameter before and after aging protocols were not of significance in any specimen subgroup, a somewhat greater mean change in translucency parameter $\Delta \mathrm{TP}$ was found in polished samples (P1-P8) (Table 4). This finding can be explained by the fact that a layer of glaze added to the base material in specimens G1-G8 had an insulating effect and minimized the impact of experimental aging protocols on the material $(37,38)$. A study by Lawson et al. confirmed the stability of the TP in the material tested in the present study Katana STML (50). The results of that study did not manifest a change in the TP of the Katana STML zirconia ceramic after two sintering programs - classical sintering, following the manufacturer's instructions, and high-speed sintering, lasting 18-30 minutes (50). Two other zirconia ceramics, Prettau Anterior and Zpex Smile, manifested a decrease in the TP value after sintering programs (50). The changes in the TP value of zirconia ceramics can be explained with a post-aging manifestation of the monoclinic phase, which leads to a formation of micro-cracks that account for porosity in the structure and result in dispersion, thus reducing translucency (51-53). The results of a study by Ledić et al. demonstrated that the TP values of glass ceramics varying in color and manufactured using different techniques did not change significantly after being immersed in a 4-percent acetic acid for 16 hours at $80^{\circ} \mathrm{C}$ (53). TP values in this research confirm the fourth hypothesis: the presence of a cubic structure resulted in translucency that is more optimized than in the previous generations of zirconia ceramics, which is line with the results of the research study by Camposilvan et al. (38). While testing the translucency, microstructure and mechanical properties of secondgeneration and third-generation zirconia ceramics, Camposilvan et al. detected structural stability, the presence of a cubic phase and translucency that was superior in the third generation of zirconia ceramics; the translucency was described as "medium", not high, and inferior to the translucency of glass ceramics. They also listed the inferior mechanical properties, which were similar to those in glass ceramics (38). This research could be supplemented by investigations into mechanical properties of the tested material as well as surface state after aging protocols $(54,55)$.

\section{Conclusions}

Within the limitations of this in-vitro study, it can be concluded that experimental aging protocols do not cause a tetragonal-to-monoclinic phase transformation, i.e. aging of materials. A fully tetragonal and a hybrid tetragonal-cubic microstructure dominate. Experimental aging protocols resulted in a certain level of color change, expressed through $\mathrm{CIE} \Delta \mathrm{E}, \mathrm{CIE} \Delta \mathrm{L}$ and $\mathrm{CIE} \Delta \mathrm{C}$ parameters; the change was površine granica zrna (49) s kojima se svjetlost susreće. Kroz tanji uzorak je transmisija svjetlosti veća $(45-48)$. S druge strane, bitno je istaknuti važnost minimalne debljine materijala koja osigurava prihvatljivu otpornost na lomljenje, a da translucencija materijala bude zadovoljavajuća $(12,43)$. Iako promjene parametra translucencije prije protokola starenja i poslije toga postupka nisu značajne ni u jednoj podskupini uzoraka, nešto veća srednja promjena parametra translucencije $\Delta \mathrm{TP}$ nastala je na uzorcima obrađenima poliranjem (P1 - P8) (tablica 4.). To se može objasniti zaštitnim djelovanjem sloja glazure na osnovni materijal kod uzoraka G1 - G8, čime se umanjuje utjecaj eksperimentalnih protokola starenja na materijal $(37,38)$. Lawson i suradnici u svojoj su studiji potvrdili stabilnost TP-a kod materijala korištenog i u ovom istraživanju - Katana STML-a (50). Ni njihovi rezultati nisu pokazali promjenu TP-a pri primjeni Katana STML cirkonijoksidne keramike nakon dvaju različitih procesa sinteriranja - klasičnoga prema uputama proizvođača i nagloga sinteriranja tijekom 18 do 30 minuta (50). Druge dvije cirkonij-oksidne keramike - Prettau Anterior i Zpex Smile - pokazale su smanjenje vrijednosti TP-a nakon procesa sinteriranja (50). Promjene u vrijednostima TP-a u primjeni cirkonij-oksidne keramike mogu se objasniti pojavnošću monoklinske faze nakon starenja koja dovodi do stvaranja mikropukotina, poput poroziteta u strukturi, i rezultiraju rasapom svjetlosti reducirajući translucenciju $(51-53)$. Rezultati K. Ledić i suradnika pokazuju da se vrijednosti TP-a staklokeramika proizvedenih različitim tehnikama i u različitoj boji nisu statistički značajno promijenile nakon izlaganja korozivnom mediju (53). Vrijednosti TP-a u ovom istraživanju potvrđuju četvrtu hipotezu, odnosno prisutnost kubične strukture rezultirala je optimiziranom translucencijom u usporedbi s prethodnim generacijama cirkonij-oksidne keramike, što je u skladu $s$ rezultatima istraživanja Camposilvana i suradnika (38). Testirajući translucenciju, mikrostrukturu i mehanička svojstva cirkonij-oksidne keramike druge i treće generacije, Camposilvan i suradnici detektirali su stabilnost strukture i prisutnost kubične faze, superiornu translucenciju treće generacije u usporedbi s cirkonijevim oksidom druge generacije koju su ujedno opisali kao srednju, a ne visoku, te inferiornu staklokeramikama. Naveli su i inferiornija mehanička svojstva, nalik na staklokeramike (38). Dopuna ovom istraživanju bila bi vezana za ispitivanje mehaničkih svojstava ovog materijala i kvalitetu površine ispitivanog materijala $(54,55)$.

\section{Zaključak}

Uključujući ograničenja ove studije in vitro, može se zaključiti da eksperimentalni protokoli starenja ne potiču tetragonsko-monoklinske fazne transformacije, odnosno starenje materijala. Dominiraju posve tetragonska mikrostruktura te kombinirana tetragonsko-kubična.

Eksperimentalni protokoli starenja rezultirali su određenim stupnjem kolornih promjena izraženih parametrima 
more pronounced in polished specimens. Unlike polishing, glazing specimens generally decreased the value of color changes CIE $\Delta \mathrm{E}, \mathrm{CIE} \Delta \mathrm{L}$ and $\mathrm{CIE} \Delta \mathrm{C}$. Light yellowing was observed in specimens subjected to aging protocols, unlike the control specimens, which did not undergo testing of any kind. These changes can be deemed clinically acceptable over a longer period of application in the conditions of the oral cavity.

Experimental aging protocols had no significant impact on translucency of third-generation monolithic zirconia ceramics, which can be explained by the presence of cubic microstructure and the absence of monoclinic phase.

\section{Conflict of interests:}

The authors declare no conflict of interests.

\section{Acknowledgements}

Science project: Defining the Possibility of Using Mini Dental Implants: the results in "in vitro" and in clinical prospective studies. (No 1218) Funded by Croatian Science Foundation, by Professor Asja Čelebić, DMD, MSc, PhD

\section{Funding}

This research did not receive any specific grant from funding agencies in the public, commercial, or not-for-profit sectors.

Author's contribution: K. M. - designed the research as a part of her doctoral thesis, conducted all experimental phases of the research, wrote the article; I. M. - assisted in color parameters measurements as well as the measurement of specimen translucency and helped with the interpretation of the results in experimental part of the research; K. M. - mentor, advisor in all phases of conducting the research and writing the article.
CIE $\Delta \mathrm{E}, \mathrm{CIE} \Delta \mathrm{L}$ i CIE $\Delta \mathrm{C}$, u većoj mjeri na poliranim uzorcima. Glazura na uzorcima općenito umanjuje veličinu kolornih promjena $\mathrm{CIE} \Delta \mathrm{E}$, CIE $\Delta \mathrm{L}$ i CIE $\Delta \mathrm{C}$ u odnosu prema uzorcima obrađenima poliranjem. Izmjereno je lagano žućenje uzoraka izloženih protokolima starenja, za razliku od kontrolnih koji nisu bili tretirani. Promjene se mogu smatrati klinički prihvatljivima tijekom dulje primjene i u uvjetima usne šupljine.

Eksperimentalni protokoli starenja ne utječu na translucenciju uzoraka treće generacije monolitne cirkonij-oksidne keramike, što se objašnjava prisutnošću stabilne kubične mikrostrukture te odsutnošću monoklinske faze.

\section{Izjava o sukobu interesa}

Autori nisu bili u sukobu interesa.

\section{Zahvala}

Objavljeni rezultati dio su projekta pod naslovom Definiranje mogucnosti uporabe minidentalnih implantata (MDI) i njihovi rezultati u in vitro i u kliničkim prospektivnim istraživanjima pod vodstvom prof. dr. sc. Asje Čelebić. Projekt je financirala Hrvatska zaklada za znanost No. 1218.

\section{Financiranje}

Ovo istraživanje nema darovatelja financijskih sredstava.

Doprinos autora: K. M. - osmislila istraživanje koje je dio njezine doktorske disertacije, provela sve eksperimentalne faze istraživanja, napisala članak; I. M. - pomogao pri provedbi mjerenja kolornih parametara i translucencije uzoraka i interpretaciji rezultata tog dijela istraživanja; K. M. - mentor, savjetnik u svim fazama provedbe i pisanja ovoga rada.

\section{Sažetak}

Svrha: Tržište dentalnih materijala u punom je zamahu kad je riječ o razvoju i plasiranju translucentnih cirkonij-oksidnih keramika. Cilj ovog istraživanja bio je ispitati utjecaj protokola starenja na mikrostrukturu, kolorne parametre i translucenciju nove generacije monolitne cirkonij-oksidne keramike. Materijal i postupci: Translucentna cirkonij-oksidna keramika KATANA-Zirconia STML s različitim načinima obrade površine (bez obrade, glazirana, polirana) testirana je u sklopu dvaju protokola starenja (hidrotermalna degradacija u autoklavu na $134^{\circ} \mathrm{C}, 2$ bara, $3 \mathrm{~h}$ i kemijska degradacija u 4-postotnoj octenoj kiselini na $80^{\circ} \mathrm{C}$ tijekom $16 \mathrm{~h}$ ) kako bi se ispitao fazni sastav rendgenskom difrakcijskom analizom, a kolorni parametri $\Delta \mathrm{E}, \Delta \mathrm{L}$ i $\Delta \mathrm{C}$ spektrofotometrijski. Iz parametara L*,a* i b* na crnoj i bijeloj podlozi izračunat je parametar translucencije (TP). Rezultati: Postupci starenja, bez obzira na način obrade površine, nisu potaknuli tetragonsko-monoklinsku faznu transformaciju, ali se kod svih testiranih uzoraka pri hidrotermalnoj degradaciji u autoklavu dogodila potpuna transformacija miješane tetragonsko-kubične strukture u tetragonsku strukturu. Značajnu kolornu promjenu $\Delta \mathrm{E}$ pokazali su svi polirani te glazirani uzorci pri kemijskoj degradaciji. Svjetlina $\Delta L$ značajno se promijenila na poliranim uzorcima koji su starjeli u autoklavu. Na svim ispitanim uzorcima zabilježena je promjena $\Delta \mathrm{C}$ u obliku žućenja koja nije statistički značajna. Pri primjeni obaju protokola starenja, translucencija se na uzorcima nije značajno promijenila. Zaključak: Starenje ne rezultira pojavom monoklinske faze u uzorcima, bez obzira na način završne obrade površine. Dominira tetragonsko-kubična mikrostruktura. Glaziranje površine translucentne cirkonij-oksidne keramike pridonosi manjim kolornim promjenama i promjenama svjetline u odnosu prema poliranju površine. Translucencija translucentne cirkonij-oksidne keramike stabilna je bez obzira na starenje i način obrade površine.
Zaprimljen: 30. ožujak 2021 Prihvaćen: 31. svibanj 2021.

Adresa za dopisivanje prof. dr. sc. Ketij Mehulić Sveučilište u Zagrebu Stomatološki fakultet Zavod za fiksnu protetiku 10000 Zagreb, Hrvatska tel: +38514802111 mehulic@sfzg.hr

MeSH pojmovi: stomatološki materijali; cirkonij

Ključne riječi: translucentna cirkonijoksidna keramika, monolitna cirkonijoksidna keramika, kubična cirkonijoksidna keramika 


\section{References}

1. Ardlin I. Transformation-toughened zirconia for dental inlays, crowns and bridges: chemical stability and effect of lowtemperature aging on flexural strength and surface structure. Dent Mater 2002;18:590-5. https://doi.org/10.1016/S0109. 5641(01)00095-1.

2. Sailer I, Makarov NA, Thoma DS, Zwahlen M, Pjetursson BE. Allceramic or metal-ceramic tooth-supported fixed dental prostheses (FDPs)? A systematic review of the survival and complication rates. Part I: Single crowns (SCS). Dent Mater 2015;15:603-23. https://doi.org/10.1016/j.dental.2015.02.011.

3. Starwarczyk B, Keul C, Eichberger M, Figge D, Edelhoff D, Lumkemann N. Three generations of zirconia: From veneered to monolithic. Part I. Quintessence Int 2017;48(5):369-80.

4. Kohorst P, Borchers L, Strempel J. Low-temperature degradation of different zirconia ceramics for dental applications. Acta Biomater 2012;8:1213-20. https://10.1016/j.actbio.2011.11.016.

5. Kawai Y, Uo M, Wang Y. Phase transformation of zirconia ceramics by hydrothermal degradation. Dent Mater 2011;30:286-92. https://doi.org/10.4012/dmj.2010-175.

6. Chevalier J, Cales B, Drouin JM. Low temperature aging of YTZP ceramics. J Am Ceram Soc 1999;82:2150-4. https://doi. org/10.1111/j.1151-2916.1999.tb02055.x.

7. Lughi V, Sergo V. Low temperature degradation -aging- of zirconia: a critical review of the relevant aspects in dentistry. Dent Mater 2010;26:807-20. https://doi.org/10.1016/j.dental.2010.04.006.

8. Papanagiotou HP, Morgano SM, Giordano RA, Pober R. In vitro evaluation of low-temperature aging effects and finishing procedures on the flexural strength and structural stability of Y-TZP dental ceramics. J Prosthet Dent 2006;96:154-64. https://doi. org/10.1016/j.prosdent.2006.08.44.

9. Kim J-W, Covel NS, Guess PC, Rekow ED, Zhang Y. Concerns of hydrothermal degradation in CAD/CAM zirconia. J Dent Res 2010;89:91-5. https://doi.org/10.1177/0022034509354193.

10. Zheng Lan L, Dan Yu J, Lei H, Guo Qiang Z, Qiang L, Cheng Z. Low temperature degradation of yttria stabilized zirconia. Mater 2007;336:1188-9. https://doi.org/10.4028/www.scientific.net/ KEM.336-338.1188.

11. Denry I, Kelly JR. Emerging ceramic based materials for dentistry. J Dent Res 2014; 93:1235-42. https://doi. org/10.1177/0022034514553627.

12. Tong H, Tanaka CB, Kaizer MR, Zhang Y. Characterization of three commercial Y-TZP ceramics produced for their high-translucency, high-strength and high-surface area. Ceram Int 2016;42:1077-85. https://doi.org/10.1016/j.ceramint.2015.09.033.

13. Zhang Y. Making yttria-stabilized tetragonal zirconia translucent. Dent Mater 2014;30:1195-203. https://doi.org/10.1016/j.dental.2014.08.375.

14. Basu B, Vleugels J, Van Der Biest O. Microstructure-toughness-wear relationship of tetragonal zirconia ceramics J Eur Ceram Soc 2004;24:2031-40. https://doi.org/10.1016/S09552219(03)00355-8.

15. Vichi A, Louca C, Corciolani G, Ferrari M. Color related to ceramic and circonia restorations: A review. Dent Mater 2011;27:97-108. https://doi.org/10.1016/j.dental.2010.10.018.

16. Zhang F, Inokoshi M, Batuk M, Hadermann J, Naert I, VanMeerbeek $B$, et al. Strength, toughness and aging stability of highly translucent Y-TZP ceramics for dental restorations. Dent Mater 2016;32:327-37. https://doi.org/10.1016/j.dental.2016.09.025.

17. Kolakarnprasert N, Kaizer MR, Kim DK, Zhang Y. New multi-layered zirconias: Composition, microstructure and translucency. Dent Mater 2019;35(5):797-806. https://doi.org/10.1016/j.dental.2019.02.017.

18. Anusavice KJ. Degradability of dental ceramics. Adv Dent Res 1992;6:82-9. https://doi.org/10.1177/08959374920060012201.

19. Jakovac M, Zivko-Babic J, Curkovic L, Aurer A. Chemical durability of dental ceramic material in acid medium. Acta Stomatol Croat 2006;40(1):65-71.

20. Muñoz EM, Longhini D, Gutierres Antonio S, Adabo GL. The effects of mechanical and hydrothermal aging on microstructure on biaxial flexural strength of an anterior and a posterior monolithic zirconia. J Dent 2017;63:94-102. https://10.1016/j. dent.2017.05.021.

21. Sulaiman JTA, Abdulmajeed AA, Shahramian K, Hupa L, Dono van TE, Vallittu $P$, et al. Impact of gastric acidic challenge on sur- face topography and optical properties of monolithic zirconia. Dent Mater 2015;31:1445-52. https://doi.org/10.1016/j.dental.2015.09.010.

22. Sulaiman TA, Abdulmajeed AA, Donovan TR, Cooper LF, Walter $R$. Fracture rate of monolithic zirconia restorations up to 5 years: a dental laboratory survey. J Prosthet Dent 2016;116(3):436-39. https://doi.org/10.1016/j.prosdent.2016.01.033.

23. Sulaiman TA, Abdulmajeed AA, Shahramian K, Lassila L. Effect of different treatments on flexural strength of fully versus partially stabilized monolithic zirconia. J Prosthet Dent 2017;118(2):21620. https://doi.org/10.1016/j.prosdent.2016.10.031.

24. Nogiwa-Valdez AA, Rainforth WM, Zeng P, Ross IM. Deceleration of hydrothermal degradation of 3Y-TZP by alumina and lanthana co-doping. Acta Biomater 2013;9:6226-35. https://doi. org/10.1016/j.actbio.2012.11.027.

25. Deville S, Chevalier J, Fantozzi G, Bartolome JF, Requena J, Moya JS, et al. Low-temperature ageing of zirconia-toughened alumina ceramics and its implication in biomedical implants. J Eur Ceram Soc 2003;23:2975-82. https://doi.org/10.1016/S09552219(03)00313-3.

26. Manicone PF, lommetti P, Raffaelli L. An overview of zirconia ceramics: Basic properties and clinical applications. J Dent 2007;35:819-26. https://doi.org/10.1016/j.dent.2007.07.008.

27. Ishikawa-Nagai S, Sato RR, Shiraishi A, Ishbashi K. Using a computer color-matching system in color reproduction of porcelain restorations. Part 3: A newly developed spectrophotometer designed for clinical application. Int J Prosthodont 1994;7(1):50-5.

28. Pensler AV. Shade selection: Problems and solutions. Compend Contin Educ Dent 1998;19:387-96.

29. Itten J. The art of color: the subjective experience and objective rationale of color. 1st ed. New York: Van Nostrand Reinhold; 1973.

30. Ruyter I, Nilner K, Möller B. Color stability of dental composite resin materials for crown and bridge veneers. Dent Mater 1987;3(5):246-51. https://doi.org/10.1016/S01095641(87)80081-7.

31. Johnston WM, Kao E. Assessment of appearance match by visual observation and clinical colorimetry. J Dent Res 1989;68(5):81922. https://doi.org/10.1177/0220345890680051301.

32. Milleding P, Karlsson S, Nyborg L. On the surface elemental composition of noncorroded and corroded dental ceramic materials in vitro. J Mater Sci Mater Med 2003;14(6):557-66. https://doi. org/10.1023/A:1023416232222.

33. Milleding $\mathrm{P}$, Wennerberg $\mathrm{A}$, Alaeddin S, Karlsson S, Simon E. Surface corrosion of dental ceramics in vitro. Biomater 1999;20(8):733-46. https://doi.org/10.1016/s01429612(98)00223-3.

34. Štefančić S. Utjecaj korozivnog medija na strukturu i svojstva zubnih keramika [The influence of a corrosive medium on structure and properties of dental ceramics] [dissertation]. Zagreb; School of Dental Medicine University of Zagreb: 2013.

35. Haralur BS, Algahtani NRS, Mujayri FA. Effect of hydrothermal aging nad beverages on color stability of lithium disilicate and zirconia based ceramics. Medicina (Kaunas) 2019;55(11):749. https://doi.org/10.3390/medicina55110749.

36. Kurt M, Bal BT. Effects of accelerated artificial aging on the translucency and color stability of monolithic ceramics with different surface treatments. J Prosthet Dent 2019;121:712-18. https:// doi.org/10.1016/j.prosdent.2019.01.014

37. Palla ES, Kontonasaki E, Kantiranis N, Papadopoulou L, Zorba T, Paraskevopoulos KM, et al. Color stability of lithium disilicate ceramics after aging and immersion in common beverages. J Prosthet Dent 2018;119(4):632-42. https://doi.org/10.1016/j.prosdent.2017.04.031.

38. Camposilvan E, Leone R, Gremillard L, Sorrentino R, Zarone F, Ferrari $M$, et al. Aging resistance, mechanical properties and translucency of different yttria-stabilized zirconia ceramics for monolithic dental crown applications. Dent Mater 2018;34(6):879-90. https://doi.org/10.1016/j.dental.2018.03.006.

39. Motro PFK, Kursoglu P, Kazazoglu E, Kursoglu P. Effects of different surface treatments on stainability of ceramics. J Prosthet Dent 2012;108(4):231-7. https://doi.org/10.1016/S00223913(12)60168-1.

40. Ledić K. Ispitivanje optičkih svojstava zubnih keramika [Analysis of optical properties of dental ceramics] [dissertation]. Zagreb; School of Dental Medicine University of Zagreb: 2015.

41. Perez MM, Ghinea R, Herrera LJ, Ionescu AM, Pomares $H$, Pulgar $\mathrm{R}$, el al. Dental ceramics: a CIEDE $_{2000}$ acceptability thresholds for 
lightness, chroma and hue differences. J Dent 2011;39:37-44. https://doi.org/10.1016/j.dent.2011.09.007.

42. Ueda K, Guth J-F, Erdelt K, Stimmelmayr M, Kappert H, Beuer F. Light transmittance by a multi-colored zirconia material. Dent Mater 2015;34(3):310-14. https://doi.org/10.4012/dmj.2014-238.

43. Vichi A, Sedda M, Fabian Fonzar R, Carrabba M, Ferrari M. Comparison of contrast ratio, translucency parameter and flexural strength of traditional and „augmented translucency“ zirconia for CEREC CAD/CAM system. J Esthet Restor Dent 2016;28:32-9. https://doi.org/10.1111/jerd.12172.

44. Abdelbary O, Wahsh M, Sherif A, Salah T. Effect of accelerated aging on translucency of monolithic zirconia. Fut Dent J 2016;2:659. https://doi.org/10.1016/j.fdj.2016.11.001.

45. Antonson SA, Anusavice KJ. Contrast ratio of venering and core ceramics as a function of thickness. Int J Prosthodont 2001;14(4):316-20.

46. Rasetto FH, Driscoll CF, Prestipino V, Masri R, von Fraunhofer JA. Light transmission through all-ceramic dental materials: a pilot study. J Prosthet Dent 2004;91(5):441-6. https://doi. org/10.1016/S0022391304001106.

47. Wang F, Takahashi H, Iwasaki N. Translucency of dental ceramics with different thicknesses. J Prosthet Dent 2015;110(1):14-20. https://doi.org/10.1016/S0022-3913(13)60333-9.

48. Cekic-Nagas I, Egilmez F, Ergun G. Comparison of light transmittance in different thicknesses of zirconia under various light curing units. J Adv Prosthodont 2012;4(2):93-6. https://doi. org/10.4047/jap.2012.4.2.93.
49. Apetz R, van Bruggen MPB. Transparent alumina: a light-scattering model. J Am Ceram Soc 2003;86:480-6. https://doi. org/10.1111/j.1151-2916.2003.tb03325.x.

50. Lawson NC, Maharishi A. Strength and translucency of zirconia after high-speed sintering. J Esthet Restor Dent 2020;32(2):219-25. https://doi.org/10.1111/jerd.12524.

51. Baldissara P, Llukacej A, Ciocca L. Translucency of zirconia copings made with different CAD/CAM systems. J Prosthet Dent 2010;104(1):6-12. https://doi.org/10.1016/S00223913(10)60086-8.

52. Heffernan MJ, Aquilino SA, Diaz-Arnold AM. Relative translucency of six all-ceramic systems. Part I: core materials. J Prosthet Dent 2002;88(1):4-9.

53. Ledić K, Majnarić I, Milardović Ortolan S, Špalj S, Štefančić S, Mehulić K. Analysis of translucency parameter of glass-ceramics fabricated by different techniques. Acta Stomatol Croat 2015;49(1):27-35. https://doi.org/10.15644/asc49/1/4

54. Štefančić S, Ćurković L, Baršić G, Majić Renjo M, Mehulić K. Investigation of glazed Y-TZP dental ceramics corrosion by surface roughness measurement. Acta Stomatol Croat. 2013;47(2):1638. https://doi.org/10.15644/asc47/2/8

55. Mešić K, Majnarić I, Obhođaš J, Baršić G, Mehulić K. The effect of aging on composition and surface of translucent zirconia ceramic. Acta Stomatol Croat. 2020;54(4):339-52. https://doi. org/10.15644/asc54/4/1 